\title{
1 Characterization of opposing responses to phenol by Bacillus subtilis chemoreceptors
}

2 Girija A. Bodhankar ${ }^{a}$, Payman Tohidifar ${ }^{a}$, Zachary L. Foust $^{b}$, George W. Ordal ${ }^{b}$, Christopher V.

$3 \mathrm{Rao}^{\mathrm{a} \#}$

4

5 aDepartment of Chemical and Biomolecular Engineering, University of Illinois at Urbana-

6 Champaign, Urbana, Illinois, USA

7 bDepartment of Biochemistry, University of Illinois at Urbana-Champaign, Urbana, Illinois, USA

10 Running Head: Phenol taxis in Bacillus subtilis

11

12 \#To whom correspondence should be addressed: Christopher V. Rao, Department of Chemical

13 and Biomolecular Engineering, University of Illinois at Urbana-Champaign, Urbana, Illinois,

14 61801, USA. Tel: 217-244-2247; Fax: 217-333-5052; Email: cvrao@illinois.edu. 


\section{ABSTRACT}

Bacillus subtilis employs ten chemoreceptors to move in response to chemicals in its environment. While the sensing mechanisms have been determined for many attractants, little is known about the sensing mechanisms for repellents. In this work, we investigated phenol

21 repellent at high, millimolar concentrations. McpA was found to be the principal chemoreceptor

22 governing the repellent response to phenol and other related aromatic compounds. In addition,

23 the chemoreceptors McpC and HemAT were found to the govern the attractant response to

24 phenol and related compounds. Using receptor chimeras, McpA was found to sense phenol

25 using its signaling domain rather than its sensing domain. These observations were

26 substantiated in vitro, where direct binding of phenol to the signaling domain of McpA was

27 observed using saturation-transfer difference nuclear magnetic resonance. These results further

28 advance our understanding of $B$. subtilis chemotaxis and demonstrate that the signaling domain

29 of $B$. subtilis chemoreceptors can directly sense chemoeffectors. 


\section{IMPORTANCE}

32 Bacterial chemotaxis is commonly thought to employ a sensing mechanism involving the

33 extracellular sensing domain of chemoreceptors. Some ligands, however, appear to be sensed

34 by the signaling domain. Phenolic compounds, commonly found in soil and root exudates,

35 provide environmental cues for soil microbes like Bacillus subtilis. We show that phenol is

36 sensed both as an attractant and a repellent. While mechanism for sensing phenol as an

37 attractant is still unknown, we found that phenol is sensed as a repellent by the signaling

38 domain of the chemoreceptor McpA. This study furthers our understanding of the unconventional sensing mechanisms employed by the $B$. subtilis chemotaxis pathway. 


\section{INTRODUCTION}

Flagellated bacteria can swim up gradients of chemicals favorable to their growth, known as attractants, and down ones inhibitory to their growth, known as repellents (1). They sense these chemicals using chemoreceptors. Bacillus subtilis, a Gram-positive soil bacterium, possesses ten chemoreceptors. Eight are transmembrane and two are soluble (2). The transmembrane chemoreceptors possess an extracellular sensing domain and an intracellular signaling domain. The extracellular sensing domain is coupled to the intracellular signaling domain by two

47 transmembrane helices, known as TM1 and TM2, and an intracellular HAMP domain (3). The soluble chemoreceptors also have signaling and sensing domains but lack the transmembrane helices and HAMP domain.

The $B$. subtilis chemoreceptors form stable complexes with the histidine kinase CheA and coupling proteins CheV and CheW $(4,5)$. These complexes form large, hexagonally structured clusters that preferentially localize at the poles of the cell $(6,7)$. These clusters are able to amplify the signaling response through allosteric interactions with neighboring chemoreceptors (8). The binding of attractants to the $B$. subtilis chemoreceptors increases the rate of CheA autophosphorylation (5). The phosphoryl group is then transferred to CheY, a soluble response regulator. Phosphorylated CheY can then bind the flagellar motors and induces them to spin counter clockwise, which causes $B$. subtilis to swim in a straight direction $(5,9)$. Presumably,

58 the binding of repellents to $B$. subtilis chemoreceptors decreases the rate of CheA 59 autophosphorylation. This, in turn, decreases the concentration of phosphorylated CheY, which 60 reduces the likelihood that the motors spin counter clockwise. When not bound with 61 phosphorylated CheY, the motors spin clockwise, which causes B. subtilis to tumble about.

62 Chemical gradients are sensed through a temporal mechanism involving sensory adaptation. $B$.

63 subtilis uses three complementary mechanisms for sensory adaptation involving receptor 64 methylation, allosteric regulation by a soluble protein known as CheD, and phosphorylation of 65 the CheV adaptor protein $(4,10,11)$. 
Multiple studies have investigated the mechanisms for sensing attractants by

67 chemoreceptors in $B$. subtilis and other diverse species of bacteria (see (12) for a

68 comprehensive review). However, far less is known about the sensing mechanisms involving

69 repellents. In this study, we investigated phenol chemotaxis in $B$. subtilis. Phenol is an attractant

70 at low, micromolar concentrations, and a repellent at high, millimolar concentrations. By

71 analyzing different mutants, McpA was found to be the principal chemoreceptor governing the

72 repellent response to phenol and other related aromatic compounds. In addition, the

73 chemoreceptors $\mathrm{McpC}$ and HemAT were found to the govern the attractant response though

74 sensing mechanisms remain unknown. Using receptor chimeras, McpA was found to sense

75 phenol using its signaling domain rather than its sensing domain. These observations were

76 substantiated in vitro, where direct binding of phenol to the signaling domain of McpA was

77 observed using saturation-transfer difference nuclear magnetic resonance. 


\section{RESULTS}

B. subtilis senses phenol as an attractant at low concentrations and a repellent at

high concentration. The chemotactic response to phenol and related aromatic compounds was measured using the capillary assay (1). In this assay, glass capillaries containing test compounds are introduced in wells filled with bacteria in chemotaxis buffer. The diffusion of these test compounds out of the capillary generates a chemical gradient. Bacteria that enter the capillary after $1 \mathrm{~h}$ of incubation are counted to quantify the chemotaxis response. The base response in the absence of a chemical gradient is determined using a control capillary containing buffer only. A colony count greater than the base count indicates an attractant response while a lower colony count indicates a repellent response. Phenol was chosen as the model compound to elucidate the chemotactic response to aromatic compounds. Phenolic compounds are abundant in nature, and chemotaxis to phenol has been studied in other bacteria (13).

The capillary assay response to increasing concentrations of phenol is shown in Fig. 1A. The number of bacteria accumulating in the capillaries was greater than the base count for capillaries containing phenol at concentrations less than $100 \mu \mathrm{M}$. A drop in the response was observed at higher concentrations. The decrease in response at higher concentrations could be due to a repellent response to phenol, loss of motility, or decreased viability of cells. Past studies have shown that the minimal inhibitory concentration of phenol for $B$. subtilis is $16 \mathrm{mM}$ (14), suggesting a repellent response instead of decreased viability. To assess repellent responses, we used the "chemical-in-pond" modification of the capillary assay (15). In this modification, capillaries are filled with chemotaxis buffer and inserted in bacterial wells, called ponds, containing the repellent. The chemotaxis response is quantified as the number of bacteria entering the capillary. A potent repellent response to phenol was observed at a concentration of $1 \mathrm{mM}$ in the pond (Fig. 1A inset). These results suggest that phenol is sensed as an attractant at low concentrations and a repellent at high concentrations. 
To understand the ligand range and preference better, we tested the chemotactic responses

to a number of aromatic compounds that differ in structures using the attractant and repellent

107 capillary assays. Benzene and toluene were selected due to their simple structures.

108 Physiologically relevant aromatics such as salicylate, benzoate, resorcinol, and p-

109 hydroxybenzoate, which are found in plant root exudates, were also tested (16). Attractant

110 assays were performed at a concentration of $1 \mu \mathrm{M}$ in the capillary (Fig. 1B). Low concentrations

111 were tested to avoid repellent effects (Fig. 1B). At $1 \mu \mathrm{M}$ concentration, toluene had high

112 attractant response. Other tested compounds except $\mathrm{p}$-hydroxybenzoic acid had slightly higher

113 responses than buffer. Repellent response was tested at $1 \mathrm{mM}$ concentration in the pond (Fig.

114 1C). At this concentration, compounds that showed high repellent response were phenol,

115 resorcinol, sodium benzoate, and sodium salicylate. A lower response was observed for

116 benzene, toluene, p-coumaric acid, and p-hydroxybenzoic acid.

117 Benzoate and salicylate are known to induce weak repellent responses in Escherichia coli 118 and Salmonella enterica at $\mathrm{pH} 5.5(17,18)$. When the external $\mathrm{pH}$ is lower than the internal $\mathrm{pH}$, 119 weak acids traverse the membrane to release protons and lower the cytoplasmic $\mathrm{pH}$. To test 120 whether the repellent response is due to a change in intracellular $\mathrm{pH}$, capillary assay 121 experiments were also carried out at a lower $\mathrm{pH}$. The motility of $B$. subtilis is reduced at $\mathrm{pH} 5.5$, 122 thus the experiments were performed at an external pH of 6 (19). The repellent responses were 123 unaffected due to the external pH change (Fig. 1D), suggesting that the response is not due to 124 pH changes.

\section{McpA is the major chemoreceptor for sensing repellents. Many repellents are}

127 membrane active compounds, and the possibility that the repellent response is due to direct 128 action on the membrane was dismissed in a previous study (20). The dose-dependent response 129 of phenol in capillary assays also hinted at a receptor-specific response. B. subtilis has ten 130 chemoreceptors (2). To identify the chemoreceptors involved in repellent sensing, we tested $B$. 
subtilis mutants expressing a single chemoreceptor with the other nine deleted (19) (Fig. 2A). Only the strain expressing McpA as its sole chemoreceptor exhibited a repellent response to phenol. To confirm this result, an $m c p A$ knockout $(\Delta m c p A)$ mutant was tested. The $\triangle m c p A$ mutant's repellent response to phenol was almost completely eliminated, confirming that McpA is the main repellent chemoreceptor (Fig. 2A inset). Other chemoreceptors may sense phenol as a repellent but, at native expression levels, their contribution is minor and McpA dominates the response. Strains expressing McpA alone were also able to mediate a repellent response to other phenolic compounds tested in this study (Fig. 2B).

Functional redundancy of attractant chemoreceptors. B. subtilis is attracted to phenol at low concentrations. In order to identify the chemoreceptors that sense phenol as an attractant, we tested single-receptor mutants using the attractant capillary assays (Fig. 2C). Mutant strains with $\mathrm{McpC}$ or HemAT as their sole chemoreceptors exhibited attractant responses to phenol. These responses were comparable to the control strain $(\triangle m c p A)$ deleted for the repellent response (Fig. $\mathbf{2 C}$ inset). It is notable that the attractant responses were not additive. Since the response to phenol at micromolar concentrations was low, higher concentrations (100 mM) of phenol were tested to compensate for the lack of signal amplification associated with allosteric interactions between chemoreceptors $(21,22)$. The strain with $\mathrm{McpC}$ as its sole chemoreceptor was able to sense other aromatic compounds as well, except p-coumaric acid and p-hydroxy benzoate (Fig. 2D). The strain with HemAT as its sole chemoreceptor sensed benzene, toluene, phenol, and resorcinol as attractants (Fig. 2D). McpC was previously found to sense amino acids and HemAT to sense oxygen and alcohols (23-25). Functional redundancy of chemoreceptors for sensing aromatic compounds is also observed in other bacteria (26).

Cytoplasmic sensing of phenol. Transmembrane chemoreceptors have a modular structure consisting of an extracellular sensing domain and a conserved, intracellular signaling 
domain. They also have a cytoplasmic HAMP domain for relaying signals between the two domains (3). It was shown that phenol sensing by $E$. coli chemoreceptors is mediated by the transmembrane helices and HAMP domain (27). In order to determine the regions of McpA involved in sensing phenol as a repellent in $B$. subtilis, we used chimeric receptors generated by swapping domains between $\operatorname{Mcp} A$ and $\operatorname{McpB}(25,28)$. McpB senses asparagine as an attractant using its extracellular sensing domain and is not involved in phenol sensing (29). This makes it a good control in order to confirm the functionality of the chimeras as well as to identify the regions of McpA involved in phenol sensing (Fig. S1A). All chimeras were expressed under the $m c p A$ promoter in a strain deleted for the native chemoreceptors.

Strains expressing a McpA-McpB chimera with the sensing domain from McpA replaced with

167 the one from $\mathrm{McpB}\left(m c p A_{44} B_{267} A\right)$ showed a repellent response to phenol and an attractant response to asparagine (Fig. 3 and Fig. S1A). This suggests that the extracellular sensing domain of McpA receptor does not sense phenol. Likewise, strains expressing a McpA-McpB chimera with the McpB signaling domain replaced with the one from $\operatorname{McpA}\left(m c p B_{359} A\right)$ showed

171 a repellent response to phenol, indicating that the transmembrane helices and HAMP domain of

$172 \mathrm{McpA}$ are not required for sensing phenol. The repellent response to phenol was eliminated in a 173 chimera where the McpA signaling domain was swapped with the McpB signaling domain $174\left(m_{c p} A_{358} B\right)$. This mutant strain, however, responded to acidic $\mathrm{pH}$ mediated by $\mathrm{McpA}$ 175 extracellular sensing domain (19), proving functionality of the chimera (Fig. S1B). These 176 observations suggest that the repellent response to phenol is mediated by the intracellular 177 signaling domain of McpA.

178 The signaling domains of chemoreceptors consist of coiled-coil helices with high sequence 179 conservation across bacteria and archaea. They have three structurally distinct subdomains: the 180 methylation helices, flexible bundle, and signaling tip (3). We tested receptor chimeras with 181 fusions near the junction of the methylation helices and flexible bundle $\left(m_{c p} B_{397} m c p A\right.$ and $\left.182 m c p B_{433} A\right)$. Cells expressing $m c p B_{397} A$ showed a repellent response to phenol while cells 
183

184

185

186

187

188

expressing $\mathrm{mcpB}_{433} A$ failed to respond to phenol but responded to asparagine normally (Fig. 3 and Fig. S1A). These results suggest that phenol is sensed by McpA using the region spanning residues 397 to 433 , which corresponds to bottom of the methylation helix and top of flexible bundle on the $\mathrm{N}$-terminus of McpA signaling of domain (see Fig. 3). Interestingly, the corresponding region on $\mathrm{McpB}$ is also involved in sensing short-chain aliphatic alcohols (C1C5), namely ethanol (25).

Docking experiments confined to phenol-sensing region on McpA were carried out to gain some insights into putative residues involved in phenol binding. Computational predictions showed that phenol conformations with the lowest docking energy scores cluster within the dimer (ranging from Glu ${ }^{397}$ to $1 \mathrm{e}^{410}$ on the $\mathrm{N}$-helix and $\mathrm{Glu}^{600}$ to $\mathrm{Ser}^{613}$ on the C-helix). Interestingly, other repellent ligands that are sensed by McpA also clustered in the same region except for salicylate (Fig. S2A and Fig. S2B). Phenylalanine, an aromatic amino acid sensed by $\mathrm{McpC}$, was used as a negative control for the docking experiments. Phenylalanine docked in a different region (residues $\mathrm{Leu}^{417}$ to $\mathrm{Ser}^{430}$ on the N-helix and $\mathrm{Asp}^{579}$ to $\mathrm{Gln}^{593}$ on the C-helix) (Fig. S2C). To assess whether these residues are important for phenol binding, we first aligned the amino-acid sequences spanning residues 397 to 410 on the N-helix and the neighboring residues 600 to 613 on the C-helix of McpA, McpB, TIpA, and TIpB (Fig. S2D). Note that these chemoreceptors are highly conserved at their signaling domain, and hence, were used to guide amino acid substitution experiments. Unfortunately, single substitution of non-conserved residues in McpA for the corresponding amino acids in McpB (N402K, A406S, S425A, A424T, M421V, S431A, S606A) did not show any change in response (data not shown).

The attractant chemoreceptors for phenol, McpC and HemAT, are phylogenetically distant from the other receptors in $B$. subtilis and, hence, not suitable for chimeric analysis in this study (Fig. S3). Indeed, chimeric receptors with the cytoplasmic domains swapped between McpA and McpC failed to respond to proline, which is sensed by the sensing domain of McpC (23). HemAT also proved to be unamenable to chimeric analysis using either McpA or YfmS (the only 
other soluble B. subtilis chemoreceptor). However, we were able to identify an aromatic attractant chemoeffector for $\mathrm{McpB}$. Cells expressing $\mathrm{McpB}$ as their sole chemoreceptor were able to sense benzene as an attractant. We were further able to identify the region involved in sensing benzene as an attractant using chimeric receptors between McpA (repellent receptor for benzene) and McpB (attractant receptor for benzene). Strains expressing the chimera $m c p B_{397} A$, involving the sensing domain of $\mathrm{McpB}$ and the signaling domain of $\mathrm{Mcp} A$, showed a repellent response to benzene. However, strains expressing the chimera $m c p B_{433} A$, which contains the previously mentioned 36 amino-acid region (residues 397 to 433) of the McpB signaling domain, showed an attractant response to benzene (Fig. S4), implying that the same region on $\mathrm{McpB}$ is also involved in sensing benzene as an attractant by $\mathrm{McpB}$.

determine whether the chemoreceptors directly bind phenol, we used ${ }^{1} \mathrm{H}$-STD-NMR (Proton Saturation-Transfer Difference Nuclear Magnetic Resonance) (30). STD-NMR is a small molecule-based NMR method for identifying ligands binding with medium to weak affinities (100 $\left.\mu \mathrm{M}<\mathrm{K}_{\mathrm{d}}<10 \mathrm{mM}\right)$. This technique exploits the transfer of magnetization from a selectively irradiated protein to a ligand in its proximity (31). Ligand protons closest to the protein will receive magnetization more efficiently (32). As the protein-ligand complex is in equilibrium, the magnetization is transferred to the bulk solution upon ligand dissociation. This is observed as a decrease in the ligand peak in the NMR spectrum (on-resonance spectrum) over that of the reference spectrum with no selective saturation (off-resonance spectrum). The difference between the on- and off-resonance spectra will only have peak intensities corresponding to the ligand protons that bound to the protein.

Fig. 4A shows the ${ }^{1} \mathrm{H}$ - and STD-NMR spectra for the signaling (McpAc) and the sensing (McpAs) domains of McpA incubated with $2 \mathrm{mM}$ phenol. Phenol protons have resonance peaks at $7.2 \mathrm{ppm}$ (meta), $6.9 \mathrm{ppm}$ (para), and $6.8 \mathrm{ppm}$ (ortho). Strong STD-NMR signals for all three 
235

236

237

238

239

240

241

242

243

244

245

246

247

248

249

250

251

252

253

254

255

256

257

258

259

proton groups were observed with the McpA signaling domain in the presence of phenol while STD-NMR signals for the McpA sensing domain incubated with the same concentration of phenol showed negligible peaks, corroborating chimeric receptor experiments. Additionally, no phenol peaks were observed for control experiment in the absence of proteins. To gain insight about the direction of phenol binding to the McpA signaling domain, we analyzed the STD amplification factor (STD-AF) for phenol protons. Briefly, the STD-AF for a proton is calculated as the ratio of integrated peak signal in the STD spectrum over the reference spectrum multiplied by ligand excess. A difference of at least $10 \%$ between ligand epitopes is recommended for classification as a preferred binding orientation (Table 1) (33). These analyses show that para proton has slightly higher STD effect compared to other protons (15\% over ortho protons and $18.9 \%$ over meta protons), suggesting that the para proton is closer to the chemoreceptor. Competitive binding experiments have been used to distinguish between specific and non-specific binding in conjunction with STD-NMR $(34,35)$. However, these experiments require a reference ligand for which the binding site on protein and binding affinity between the two are known. Since such ligand was unknown for these experiments, we instead conducted the STD-NMR experiments for the McpB signaling domain in the presence of excess phenol to provide an additional negative control. The rational for this experimental design was that the McpB signaling domain has a coiled-coil structure with $74 \%$ sequence identity to the McpA signaling domain. As expected, negligible phenol peaks (STD-AF < 4\%) were observed in the STD spectrum (Fig. S5A). Finally, we conducted a control STD-NMR experiment with phenylalanine. Phenylalanine is an aromatic amino acid sensed by the McpC sensing domain with weak binding affinity (23). No signals corresponding to the ligand were observed in the STD spectrum of McpA signaling domain incubated with $2 \mathrm{mM}$ phenylalanine (Fig. S5B). Chimeric receptor experiments suggested that the $\mathrm{McpB}$ signaling domain is involved in sensing benzene. STD spectrum of McpB signaling domain in the presence of $2 \mathrm{mM}$ benzene showed a 
260

261

262

263

264

265

266

267

268

269

270

271

272

273

274

275

276

277

278

279

280

281

282

283

284

285

peak associated with benzene moiety with STD-AF of $16.4 \%$, implying direct interaction of benzene with the McpB signaling domain (Fig. S5C).

In the case of HemAT, phenol peaks were observed in the STD spectra for both the sensing and signaling domains (Fig. 4B). The para proton had the highest STD-AF values; however, the difference between STD-AF values within different moieties was too close to the $10 \%$ threshold described above. Therefore, it is difficult to classify this as a preferred binding direction. As negative controls, no binding was observed between phenylalanine and either HemAT domain. HemAT is a soluble chemoreceptor that contains a heme group for sensing molecular oxygen $(36,37)$. The sensing domain dimer interface consists of a four helical bundle at its core with other helices packed around it. HemAT sensing domain helices are hypothesized to be involved in sensing ethanol (25), and phenol likely follows a similar mechanism. The signaling domain of HemAT has a coiled-coil conserved structure similar to that of McpA. Surprisingly, the STD spectra for phenol and the McpC sensing and signaling domains were negligible (Fig. 4C). This suggests that phenol is probably sensed by the transmembrane helices or the HAMP domain of McpC.

We next used STD-NMR to determine the affinity of phenol for the signaling domain of McpA. STD-NMR titration experiments at different ligand concentrations can be used to determine the binding affinity $\left(\mathrm{K}_{\mathrm{d}}\right)$ of a protein-ligand complex. However, STD signals also rely on the kinetics of protein-ligand rebinding. The method of initial growth rates, where STD factors are calculated at the limit of zero saturation time (no protein-ligand rebinding), has been successfully used in an earlier report for determining $K_{d}$ values (38). Briefly, STD-AF values were first calculated at different saturation times to get the initial-slope for each concentration (STD-AF0) (Fig. 5A). Initial slope values were then plotted against ligand concentrations to determine the $\mathrm{K}_{\mathrm{d}}$ using the Langmuir isotherm curve. The binding affinity to phenol was calculated as $4.8 \mathrm{mM}$ with McpA's signaling domain (Fig. 5B). It is important to note that the binding curve for phenol and McpA signaling domain pair followed the hyperbolic curve model 
286 with a decreasing slope at higher phenol concentrations indicative of a specific binding event.

287 However, at higher phenol concentrations (>4 mM), non-specific binding dominates, and the

288 curve increased linearly instead of reaching a plateau. As a consequence, the $\mathrm{K}_{d}$ is 289 overestimated in this study. The overestimation of binding $\mathrm{K}_{\mathrm{d}}$ values has also been reported in 290 another STD-NMR study and orthogonal techniques are recommended for obtaining accurate 291 values $(33,38)$. As such, we conducted isothermal titration calorimetry experiments to assess 292 the binding between McpA signaling domain and phenol. Unfortunately, these experiments were 293 not conclusive because the affinity is weak (data not shown). In the case of HemAT, the phenol 294 binding mechanism appears to be rather complex as phenol directly interacts with both sensing 295 and signaling domains of HemAT. 


\section{DISCUSSION}

Previous studies reported several membrane-active agents are repellents for $B$. subtilis (39). Initially, it was unknown whether repellents are sensed by receptors or the membrane through changes in fluidity. Later, it was shown that repellents are sensed by chemoreceptors; however,

302 their identities were unknown $(40,41)$. In this work, we found that the repellent receptor for

303 phenol is McpA, a transmembrane chemoreceptor that also senses external acidic $\mathrm{pH}(19)$.

304 McpA was found to be a broad-range chemoreceptor and capable of sensing multiple other

305 aromatic compounds as repellents. Our data indicate that phenol is sensed by the cytoplasmic 306 signaling domain of McpA. This contrasts the more common mechanism where chemoeffectors bind the extracellular sensing domain to induce signaling. That said, multiple examples of sensing by the signaling domain have been documented in the literature. For example, the region below the HAMP domain was also found to be important for sensing toluene and oxylene by the Tar chemoreceptor in E. coli (42). Phenol sensing in E. coli also follows an

311 unconventional route where phenol appears to bind the transmembrane helices and HAMP 312 domain (27). In addition, the PctA chemoreceptor from Pseudomonas aeruginosa senses

313 chlorinated compounds as repellents, but no binding was observed with the extracellular 314 sensing domain of the chemoreceptor (43). Lastly, ethanol is sensed by the signaling domain of 315 McpB in B. subtilis (25).

Chimeric receptor analysis revealed the importance of amino-acid residues near the junction

317 of $\mathrm{N}$-terminal methylation helices and flexible bundle in McpA. In case of attractant sensing, 318 benzene also appears to be sensed by the same region in McpB. Swapping the 36 amino-acid 319 regions between $\mathrm{McpA}$ and $\mathrm{McpB}$ chemoreceptors converted the repellent response of $\mathrm{McpA}$ to 320 an attractant response, and vice versa for $\mathrm{McpB}$. This region was also important for sensing 321 ethanol by the signaling domain of $\operatorname{McpB}(25)$. Molecular dynamics simulations and mutation 322 studies correlated changes in coiled-coil packing of the signaling domain with ability of McpB to 323 sense ethanol. While the exact mechanism for signal propagation in chemoreceptors is still 
324 being resolved, kinase activity is thought to be modulated by changes in chemoreceptor 325 dynamics that propagate the signal through HAMP and signaling domains (44-46). Recent 326 studies have characterized chemoreceptor flexibility and dynamics in different signaling states.

327 Electron paramagnetic resonance (EPR) studies have shown that the $\mathrm{N}$-terminal methylation 328 helices have different dynamics as compared to the C-terminal tail of the chemoreceptor in both 329 methylated and demethylated states (47-49). Mobility of the $\mathrm{N}$-terminal methylation helices was 330 proposed to be a key signaling element in hydrogen exchange and solid-state NMR studies (50, 331 51). Cryoelectron tomography and molecular dynamics simulation studies of the E. coli Tsr 332 chemoreceptor showed the importance of the glycine hinge (present in the flexible bundle region) in controlling chemoreceptor compactness and flexibility to allow for different signaling 334 states $(52,53)$. It is possible that ligands like phenol and ethanol interact with signaling domain helices and cause changes in receptor packing or mobility, thus mimicking traditional signals that would have been propagated from the sensing domain via HAMP region. However, the exact mechanism of phenol sensing by McpA chemoreceptor remains unknown. transmembrane chemoreceptor involved in sensing amino acids and sugars $(23,54)$. It is unclear how phenol induces signaling in $\mathrm{McpC}$ as no interaction between phenol and the sensing or signaling domains was observed by STD-NMR. These experiments fail to detect tight

342 binding events (affinities in nanomolar-micromolar range) (38). Because the exchange of ligand 343 is slow, the transfer to bulk solution is low and weak signals are observed. Another possibility is 344 that phenol interacts with the transmembrane helices or HAMP domain of McpC in a manner 345 similar to Tar and Tsr in E. coli (27); however, the possibility of an indirect sensing mechanism 346 cannot be ruled out. The McpC sensing domain senses many amino acids indirectly though 347 membrane associated proteins (23) while the signaling domain is involved in sugar taxis through 348 interactions with the phosphotransferase system (PTS) (54). Thus, phenol could induce 349 signaling through an indirect interaction. HemAT, on the other hand, is a cytoplasmic heme 
containing receptor known to sense molecular oxygen (24). Both the sensing and signaling domains of HemAT receptor bound phenol in the STD-NMR experiments. The sensing domain of HemAT is also involved in recognizing ethanol although the heme group is not involved (25). How phenol induces different output responses for different receptors is still an open-ended question.

Phenol is a complex chemoeffector and induces both attractant and repellent responses in E. coli and S. enterica $(13,55)$. The overall response is dependent on the relative abundance of 357 different chemoreceptors (56). HemAT and McpA are the two most abundant receptors in $B$. subtilis (19,000 $\pm 3,900 /$ cell and 15,900 $\pm 3,000$ /cell, respectively) while McpC chemoreceptor concentrations are low (2,800 \pm 640 /cell) (2). Unlike E. coli and S. enterica, the overall response to phenol in $B$. subtilis does not appear to be dictated by the relative abundance of its chemoreceptors. It is possible that a different mechanism, such as the biphasic adaptation response described for indole, is at play (57). In particular, E. coli cells previously adapted to roughly $700 \mu \mathrm{M}$ indole showed an attractant response to high indole concentrations $(2 \mathrm{mM})$ in chemotaxis assays while a repellent response was seen for unprimed cells. However, $B$. subtilis cells were not previously adapted to phenol in our capillary assay experiments. One possibility is that the overall response depends on the kinetics and conformational changes induced upon binding of phenol to the three chemoreceptors. Unfortunately, capillary assays are limited in quantifying the exact effect of phenol addition or removal. For example, we have previously found that the chemoeffector concentrations experienced by the cells near the capillary are 1050 times lower than the initial concentration inside the capillary (25). The attractant and repellent

371 capillary assays are also optimized at different cells and chemoeffector concentrations, which 372 limits direct comparison of opposing responses induced by a chemoeffector. The mechanism of 373 inversion of attractant to repellent response is a topic of ongoing study.

374 Phenolic compounds are ubiquitous in nature (58). Plant root exudates contain phenolic 375 compounds that act as signaling molecules for plant-microbe interactions $(59,60)$. Chemotaxis 
to plant root exudates has been shown to be important for root colonization (61). B. subtilis is a

377 member of plant-growth promoting rhizobacteria (62). Root exudates from soybean and rice

378 plants are known to attract Bacillus amyloliquefaciens and Bacillus spp $(16,63)$. Chemotaxis

379 was also found to be essential for early root colonization of Arabidopsis thaliana by B. subtilis

380 (64). This study also reported an increase in the chemotaxis response to root exudates by a

$381 \triangle m c p A$ strain. As McpA was found to be the major repellent chemoreceptor for phenol and

382 other aromatic compounds in this study, the increased chemotaxis response in the $\Delta m c p A$

383 strain can be explained as due to loss of the repellent chemoreceptor. Other compounds

384 including p-hydroxybenzoic acid, vanillyl alcohol, and isoflavones are known chemoattractants

385 for Agrobacterium and Rhizobium species of Rhizobiaceae family (60). Certain phenolic

386 compounds such as salicylic acid and hydroxycoumarins are also produced by plants in

387 response to pathogen attacks (59). Salicylic acid was reported to be a repellent for $B$.

388 amyloliquefaciens (16). The presence and concentration of phenolic compounds in root

exudates thus changes according to many factors. Changing attractant and repellent

chemotaxis responses to aromatics at different concentrations likely helps $B$. subtilis navigate

B. subtilis exhibits complex predator-prey relationships with many microorganisms and are known to release many antifungal and antibiotic compounds (68-70). Therefore, chemotaxis response to aromatics may also help $B$. subtilis find prey and evade predators.

397 Phenolic compounds are also classified as pollutants and cause various harmful effects in 398 humans and animals. These compounds are primarily found in industrial wastes, forest fires, 399 and are released to the environment through anthropogenic activities. Bioremediation strategies 400 based on microbial decomposition of phenolic compounds are being used widely to remove 401 phenols from wastewater $(71,72)$. Chemotaxis towards environmental pollutants can be 
402 exploited to guide bacteria and locate pollutants in the environment. As more reports of novel

403 bacterial species responding to pollutants are being reported $(26,73)$, understanding of

404 underlying mechanisms of chemotaxis is essential to enable design of new strategies facilitating

405 bioavailability of pollutants for degradation.

406 


\section{ACKNOWLEDGEMENT}

408 We thank Dr. Lingyang Zhu, Dr. Dean Olson, and the SCS NMR laboratory at the

409 University of Illinois at Urbana-Champaign for valuable inputs and help with NMR

410 measurements. This work was partially funded by National Institutes of Health Grant

411 GM054365 and by the University of Illinois through the Robert W. Schaefer Faculty

412 Scholar fund.

413 


\section{MATERIALS AND METHODS}

Chemicals, media, and growth conditions: B. subtilis strains were routinely grown on tryptose blood agar base plates (TBAB: $1 \%$ tryptone, $0.3 \%$ beef extract, $0.5 \% \mathrm{NaCl}$, and $1.5 \%$

417 agar) at $30{ }^{\circ} \mathrm{C}$ for $16 \mathrm{~h}$. Chemotaxis experiments were performed with capillary assay minimal 418 media (CAMM: $50 \mathrm{mM}$ potassium phosphate buffer (pH 7.0), $1.2 \mathrm{mM} \mathrm{MgCl}_{2}, 0.14 \mathrm{mM} \mathrm{CaCl}, 1$ $419 \mathrm{mM}\left(\mathrm{NH}_{4}\right)_{2} \mathrm{SO}_{4}, 0.01 \mathrm{mM} \mathrm{MnCl}_{2}$, and $42 \mu \mathrm{M}$ ferric citrate). Chemotaxis buffer consists of $10 \mathrm{mM}$ 420 potassium phosphate buffer ( $\mathrm{pH} 7.0), 0.14 \mathrm{mM} \mathrm{CaCl} 2,0.3 \mathrm{mM}\left(\mathrm{NH}_{4}\right)_{2} \mathrm{SO}_{4}, 0.1 \mathrm{mM}$ EDTA, $5 \mathrm{mM}$ 421 sodium lactate, and $0.05 \%(\mathrm{v} / \mathrm{v})$ glycerol. All aromatic compounds were reagent grade and above. Chemicals were purchased from Sigma and Fisher.

Strains and plasmids: All $B$. subtilis strains were derived from the chemotactic strain Ol1085 (74). The strains and plasmids used in this work are listed in Tables 2 and $\mathbf{3}$, respectively. All cloning was performed using NEBß 5-alpha Competent E. coli (New England

427 Biolabs).

Receptor chimeras were constructed according to the procedure described previously (25) .

429 Briefly, the region outside the fusion points was amplified by whole plasmid PCR with the pAIN750mcpA plasmid as the template. The desired fragments from $m c p B$ were amplified from pAIN750mcpB with a short overlap on both ends. The PCR products were purified after gel extraction, assembled using Gibson assembly (75), and transformed in E. coli. After sequence verification, the correct plasmids were linearized at the Xhol restriction site, re-ligated, and

434 transformed into B. subtilis Ol3545 (receptorless mutant) using the two-step Spizizen method 435 (76). Colonies were screened for spectinomycin resistance and integration in the amyE locus 436 was verified using Gram iodine solution (0.33\% iodine, $0.66 \%$ potassium iodide, and $1 \%$ sodium 437 bicarbonate) on starch plates. Correct clones were unable to hydrolyze starch and form clear 438 zones. 
For construction of chimeric receptors under the control of the $m c p A$ promoter, whole plasmid PCR was used to amplify the pAIN750mcpA plasmid excluding the mcpA region to be swapped by the desired region from another receptor. The desired region from another receptor

442 was also PCR-amplified with overlapping primers and both DNA fragments were purified and 443 assembled with Gibson assembly. Point mutations were performed as described previously 444 (25).

445 Cloning for recombinant protein production was performed in E. coli BL21(DE3). The DNA 446 fragments corresponding to the signaling domain of McpA (residues 359 to 661 ) and McpB

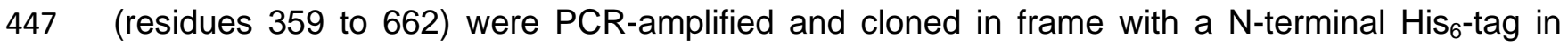
$448 \mathrm{pET} 28 \mathrm{a}(+)$ plasmid at Nhel restriction site using Gibson assembly. . McpA sensing domain

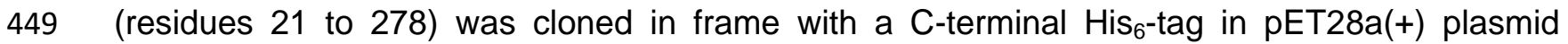
450 between the $\mathrm{Xhol}$ and $\mathrm{Ncol}$ restriction sites. McpC sensing domain (residues 33 to 278) was 451 cloned in frame with a N-terminal $\mathrm{His}_{6}$-tag in $\mathrm{pET} 28 \mathrm{a}(+)$ at the Ndel restriction site using Gibson 452 assembly. Assembled plasmids were transformed in E. coli.. After isolation and sequence 453 verification, all plasmids were transformed into E. coli BL21(DE3) strain for protein expression 454 and purification. was used for quantifying repellent chemotaxis responses (PMID: 4597449). Briefly, B. subtilis strains were grown for $16 \mathrm{~h}$ at $30^{\circ} \mathrm{C}$ on TBAB plates. The cells were scraped from the plates

459 and resuspended to $O D_{600}=0.03$ in $5-\mathrm{mL}$ CAMM supplemented with $50 \mu \mathrm{g} / \mathrm{mL}$ histidine, 50 $460 \mu \mathrm{g} / \mathrm{mL}$ methionine, $50 \mu \mathrm{g} / \mathrm{mL}$ tryptophan, $20 \mathrm{mM}$ sorbitol, and $2 \%$ TB. The cultures were then 461 grown to $O D_{600}=0.4-0.45$ at $37{ }^{\circ} \mathrm{C}$ with shaking at $250 \mathrm{rpm}$, after which $50 \mu \mathrm{L}$ of $\mathrm{GL}$ solution $462(5 \%(\mathrm{v} / \mathrm{v})$ glycerol and $0.5 \mathrm{M}$ sodium lactate) was added, and cells were incubated for another $46315 \mathrm{~min}$. The cells were then washed twice with chemotaxis buffer and incubated for additional $46425 \mathrm{~min}$ at $37^{\circ} \mathrm{C}$ with shaking at $250 \mathrm{rpm}$ to assure that the cells were motile. Cells were then 
diluted to $O D_{600}=0.01$ in chemotaxis buffer containing appropriate concentrations of repellents.

466 The culture was shaken for $10 \mathrm{~min}$ at room temperature, shaking at $150 \mathrm{rpm}$ and then aliquoted

467 into $0.3-\mathrm{mL}$ ponds on a slide warmer at $37^{\circ} \mathrm{C}$. Closed-end capillary tubes filled with chemotaxis

468 buffer were inserted in the ponds. After $1 \mathrm{~h}$, cells in the capillaries were harvested and

469 transferred to $3 \mathrm{~mL}$ of top agar ( $1 \%$ tryptone, $0.8 \% \mathrm{NaCl}, 0.8 \%$ agar, and $0.5 \mathrm{mM}$ EDTA) and

470 plated onto TB agar (TB and $1.5 \%$ agar) plates. These plates were incubated for $16 \mathrm{~h}$ at $37^{\circ} \mathrm{C}$

471 and colonies were counted. Experiments were performed in triplicate each day and repeated on

472 three different days. Attractant assays for aromatic compounds were carried out at $O D_{600}=$

4730.001 for $1 \mathrm{~h}$. For testing functionality of the mutant strains expressing chimeric receptors,

474 attractant assays were performed for $30 \mathrm{~min}$ with cells diluted to $O D_{600}=0.001$ in the pond and

475 asparagine solution $(3.16 \mu \mathrm{M})$ in the capillary. For measuring chemotaxis response to external

acidic $\mathrm{pH}$, capillaries filled with chemotaxis buffer at $\mathrm{pH} 7.0$ were inserted in the pond containing

477 cells at $O D_{600}=0.001$ preadapted to $\mathrm{pH} 8.0$ in chemotaxis buffer and cells in the capillaries

were harvested after $1 \mathrm{~h}$ and counted as described above (19).

Protein purification: E. coli BL21(DE3) cells harboring the $\mathrm{His}_{6}$-tagged expression min. Cells were resuspended in lysis buffer $\left(50 \mathrm{mM} \mathrm{NaH}_{2} \mathrm{PO}_{4}, 300 \mathrm{mM} \mathrm{NaCl}, 10 \mathrm{mM}\right.$ Imidazole, $\mathrm{pH} 8$ ) and sonicated (5 $\times 10 \mathrm{~s}$ pulses). After centrifugation at $40,000 \times \mathrm{g}$ for $1 \mathrm{~h}$, the supernatant

487 was loaded on a $5 \mathrm{~mL}$ GE Hi-Trap Chelating column charged with $0.1 \mathrm{M} \mathrm{NiSO}_{4}$ and binding 488 buffer $\left(50 \mathrm{mM} \mathrm{NaH}_{2} \mathrm{PO}_{4}, 300 \mathrm{mM} \mathrm{NaCl}, 20 \mathrm{mM}\right.$ imidazole, $\mathrm{pH}$ 8). The protein-bound column 489 was then washed with 10 column volumes of binding buffer and proteins were eluted with 490 imidazole gradient of 20-500 mM. The collected protein fractions were pooled and concentrated 
491

492

493

494

495

496

497

498

499

500

501

502

503

504

505

506

507

508

509

510

511 512 stacked mode.

513

514

using an Amicon ultrafiltration cell (Millipore) and dialyzed into PBS (10 mM Na $2 \mathrm{HPO}_{4}, 1.8 \mathrm{mM}$ $\left.\mathrm{KH}_{2} \mathrm{PO}_{4}, 137 \mathrm{mM} \mathrm{NaCl}, 2.7 \mathrm{mM} \mathrm{KCl}, \mathrm{pH} 7.4\right)$ at $4{ }^{\circ} \mathrm{C}$. HemAT domains were purified as described before (25). Aliquots were stored at $-80^{\circ} \mathrm{C}$. Concentration of purified proteins was measured by the Pierce BCA protein assay kit.

\section{Saturation-transfer difference nuclear magnetic resonance spectroscopy (STD-NMR):}

All NMR spectroscopy measurements were performed on a Varian VNMRS instrument at 750 $\mathrm{MHz}$ with $5 \mathrm{~mm}$ Varian $\mathrm{HCN}$ probe at $298 \mathrm{~K}$ without sample spinning. Prior to measurements, protein samples were buffer exchanged into PBS (50 mM KH${ }_{2} \mathrm{PO}_{4}, 20 \mathrm{mM} \mathrm{NaCl}, \mathrm{pH} 7.4$ ) in $\mathrm{D}_{2} \mathrm{O}$ using Micro Bio-Spin ${ }^{\circledR}$ Columns with Bio-Gel® P-6 (Bio-Rad Laboratories). Protein (final concentration $20 \mu \mathrm{M}$ ) and ligand samples (final concentration $2 \mathrm{mM}$ ) were added to the NMR tube at $500 \mu \mathrm{L}$ solution volume. For $\mathrm{K}_{d}$ measurements, ligand concentrations were varied from $0.5 \mathrm{mM}$ to $4 \mathrm{mM}$. ${ }^{1} \mathrm{H}$ spectra were obtained from 32 scans with a 90 -degree pulse and a $2-\mathrm{s}$ relaxation delay. In STD-NMR experiments, the protein samples were selectively saturated at $0.5 \mathrm{ppm}$ with a train of Gaussian pulses of $50 \mathrm{~ms}$ duration with $0.1 \mathrm{~ms}$ delay and $5 \mathrm{~s}$ relaxation delay for a total saturation time of $1-4 \mathrm{~s}$ and 256 scans. Off-resonance irradiation was applied at $30 \mathrm{ppm}$. Trim pulse of $50 \mathrm{~ms}$ was used to reduce protein background. All STD spectra were obtained by phase cycling after a block size of 8 to reduce artifacts resulted from temperature variation and magnet instability. Manual subtraction was performed to obtain the difference spectra. Control experiments were performed on samples containing only ligands without protein. All areas were calculated using MNova V14.1 (Mestrelab chemistry solutions) in

The STD amplification factor (STD-AF) is defined as the fractional saturation of a given proton multiplied by the excess of the ligand over the protein (38).

$$
S T D-A F=\left(\frac{I_{0}-I_{s a t}}{I_{0}}\right) \frac{L}{P}
$$


515 The method of initial slopes was used to determine the dissociation constant $\left(\mathrm{K}_{\mathrm{d}}\right)(38,77)$. The

516 STD amplification factors at initial slopes $\left(S T D-A F_{0}\right)$ for each ligand concentration were

517 calculated by plotting the STD-AF evolution with saturation times and fitting the equation:

$$
S T D-A F_{t}=S T D_{\max }\left(1-e^{-k_{s a t} t}\right)
$$

518 The initial slope was then obtained by taking the derivative at $t=0$, yielding:

$$
S T D-A F_{0}=S T D_{\max } k_{s a t}
$$

519 Plotting STD-AF 0 values against the increasing ligand concentrations $(\mathrm{L})$ would yield a Langmuir 520 hyperbolic dose-response curve. Finally, the dissociation constant $\left(K_{d}\right)$ was calculated by fitting 521 the data to the following equation:

$$
S T D-A F_{0}=\frac{\alpha L}{L+K_{d}}
$$

Phylogenetic tree and structural analyses of chemoreceptor domains: $B$. subtilis

524 (RefSeq: GCF_000009045.1) chemoreceptor sequences were obtained from MiST 3.0 database (78). Tree analysis was carried out using TREND platform (79). Protein sequences were first aligned with the online version of MAFFT (80) and the alignment result was then used

527 as an input in FastTree program (81) to construct the tree. Domain predictions was performed using HMMER3 (82).

In-silico docking experiments: The dimer structure of McpA signaling domain (residues 531352 to 661) was constructed using Modeller (v-9.23) (83). The homology model was based on 532 Thermotoga maritima Tm113 chemoreceptor (PDB 2CH7) (84). Side-chain conformations were 533 refined using SCWRL4 (85) and the resulting protein structure was minimized using YASARA 534 server (86). 3D structures of the ligands were obtained from Pubchem (87). Docking 535 experiments were carried out using Autodock Vina (v-1.1.2) (88) in which the grid size was set 
536 to $58 \times 50 \times 62$ points with $1 \AA$ spacing surrounding residues 391 to 436 and exhaustiveness

537 was set at 10. Clusters were visualized using Autodock Tools GUI (89).

539 Data availability. Raw data are provided as Supplemental Dataset 1. 
bioRxiv preprint doi: https://doi org/10.1101/2021.08.31.458471. this version posted September 1, 2021. The copyright holder for this preprint

(which was not certified by peer review) is the author/funder, who has granted bioRxiv a license to display the preprint in perpetuity. It is made available under aCC-BY-NC-ND 4.0 International license.

\section{ACKNOWLEDGEMENTS}

542 This work was supported by the University of Illinois through the Robert W. Schaefer Faculty

543 Scholar fund.

544 


\section{REFERENCES}

546 1. Adler J. 1976. Chemotaxis in bacteria. J Supramol Struct 4:305-17.

547 2. Cannistraro VJ, Glekas GD, Rao CV, Ordal GW. 2011. Cellular stoichiometry of the chemotaxis proteins in Bacillus subtilis. J Bacteriol 193:3220-7.

3. Alexander RP, Zhulin IB. 2007. Evolutionary genomics reveals conserved structural determinants of signaling and adaptation in microbial chemoreceptors. Proc Natl Acad Sci U S A 104:2885-90.

4. Walukiewicz HE, Tohidifar P, Ordal GW, Rao CV. 2014. Interactions among the three adaptation systems of Bacillus subtilis chemotaxis as revealed by an in vitro receptorkinase assay. Mol Microbiol 93:1104-18.

556

5. Garrity LF, Ordal GW. 1997. Activation of the CheA kinase by asparagine in Bacillus subtilis chemotaxis. Microbiology (Reading) 143:2945-2951.

6. Wu K, Walukiewicz HE, Glekas GD, Ordal GW, Rao CV. 2011. Attractant binding induces distinct structural changes to the polar and lateral signaling clusters in Bacillus

7. Briegel A, Ortega DR, Tocheva El, Wuichet K, Li Z, Chen S, Muller A, lancu CV, Murphy GE, Dobro MJ, Zhulin IB, Jensen GJ. 2009. Universal architecture of bacterial chemoreceptor arrays. Proc Natl Acad Sci U S A 106:17181-6.

8. Zimmer MA, Szurmant H, Saulmon MM, Collins MA, Bant JS, Ordal GW. 2002. The role of heterologous receptors in McpB-mediated signalling in Bacillus subtilis chemotaxis. Mol Microbiol 45:555-68.

9. Szurmant H, Bunn MW, Cannistraro VJ, Ordal GW. 2003. Bacillus subtilis hydrolyzes CheY-P at the location of its action, the flagellar switch. J Biol Chem 278:48611-6.

10. Rao CV, Glekas GD, Ordal GW. 2008. The three adaptation systems of Bacillus subtilis chemotaxis. Trends Microbiol 16:480-7. 
570 11. Rao CV, Ordal GW. 2009. The Molecular Basis of Excitation and Adaptation during Chemotactic Sensory Transduction in Bacteria, p 33-64, Bacterial Sensing and Signaling doi:10.1159/000219372.

573 12. Ortega A, Zhulin IB, Krell T. 2017. Sensory Repertoire of Bacterial Chemoreceptors. Microbiol Mol Biol Rev 81.

575 13. Imae Y, Oosawa K, Mizuno T, Kihara M, Macnab RM. 1987. Phenol: a complex chemoeffector in bacterial chemotaxis. J Bacteriol 169:371-9.

577 14. Tam le T, Eymann C, Albrecht D, Sietmann R, Schauer F, Hecker M, Antelmann H. 2006. Differential gene expression in response to phenol and catechol reveals different metabolic activities for the degradation of aromatic compounds in Bacillus subtilis.

15. Tso WW, Adler J. 1974. Negative chemotaxis in Escherichia coli. J Bacteriol 118:560-76.

582 16. Feng $\mathrm{H}$, Zhang $\mathrm{N}$, Du W, Zhang H, Liu Y, Fu R, Shao J, Zhang G, Shen Q, Zhang R. 2018. Identification of Chemotaxis Compounds in Root Exudates and Their Sensing Chemoreceptors in Plant-Growth-Promoting Rhizobacteria Bacillus amyloliquefaciens SQR9. Mol Plant Microbe Interact 31:995-1005.

17. Kihara M, Macnab RM. 1981. Cytoplasmic $\mathrm{pH}$ mediates $\mathrm{pH}$ taxis and weak-acid repellent taxis of bacteria. J Bacteriol 145:1209-21.

18. Repaske DR, Adler J. 1981. Change in intracellular pH of Escherichia coli mediates the chemotactic response to certain attractants and repellents. J Bacteriol 145:1196-208.

590 19. Tohidifar P, Plutz MJ, Ordal GW, Rao CV. 2020. The Mechanism of Bidirectional pH Taxis in Bacillus subtilis. J Bacteriol 202.

592 20. Ordal GW. 1976. Recognition sites for chemotactic repellents of Bacillus subtilis. J $593 \quad$ Bacteriol 126:72-9.

594 21. Gestwicki JE, Kiessling LL. 2002. Inter-receptor communication through arrays of $595 \quad$ bacterial chemoreceptors. Nature 415:81-4. 
596

597

598

599

600

601

602

603

604

605

606

607

608

609

610

611

612

613

614

615

616

617

618

619

620

621

22. Sourjik V, Berg HC. 2004. Functional interactions between receptors in bacterial chemotaxis. Nature 428:437-41.

23. Glekas GD, Mulhern BJ, Kroc A, Duelfer KA, Lei V, Rao CV, Ordal GW. 2012. The Bacillus subtilis chemoreceptor $\mathrm{McpC}$ senses multiple ligands using two discrete mechanisms. J Biol Chem 287:39412-8.

24. Hou S, Larsen RW, Boudko D, Riley CW, Karatan E, Zimmer M, Ordal GW, Alam M. 2000. Myoglobin-like aerotaxis transducers in Archaea and Bacteria. Nature 403:540-4.

25. Tohidifar P, Bodhankar GA, Pei S, Cassidy CK, Walukiewicz HE, Ordal GW, Stansfeld PJ, Rao CV. 2020. The Unconventional Cytoplasmic Sensing Mechanism for Ethanol Chemotaxis in Bacillus subtilis. mBio 11.

26. Wang YH, Huang Z, Liu SJ. 2019. Chemotaxis Towards Aromatic Compounds: Insights from Comamonas testosteroni. Int J Mol Sci 20.

27. Pham HT, Parkinson JS. 2011. Phenol sensing by Escherichia coli chemoreceptors: a nonclassical mechanism. J Bacteriol 193:6597-604.

28. Bi S, Pollard AM, Yang Y, Jin F, Sourjik V. 2016. Engineering Hybrid Chemotaxis Receptors in Bacteria. ACS Synth Biol 5:989-1001.

29. Glekas GD, Foster RM, Cates JR, Estrella JA, Wawrzyniak MJ, Rao CV, Ordal GW. 2010. A PAS domain binds asparagine in the chemotaxis receptor McpB in Bacillus subtilis. J Biol Chem 285:1870-8.

30. Mayer M, Meyer B. 1999. Characterization of Ligand Binding by Saturation Transfer Difference NMR Spectroscopy. Angew Chem Int Ed Engl 38:1784-1788.

31. Meyer B, Peters T. 2003. NMR spectroscopy techniques for screening and identifying ligand binding to protein receptors. Angew Chem Int Ed Engl 42:864-90.

32. Viegas A, Manso J, Nobrega FL, Cabrita EJ. 2011. Saturation-Transfer Difference (STD) NMR: A Simple and Fast Method for Ligand Screening and Characterization of Protein Binding. Journal of Chemical Education 88:990-994. 
622 33. Cala O, Krimm I. 2015. Ligand-Orientation Based Fragment Selection in STD NMR

623

624

625

626

627

628

629

630

631

632

633

634

635

636

637

638

639

640

641

642

643

644

645

646

647

Screening. J Med Chem 58:8739-42.

34. Szczepina MG, Zheng RB, Completo GC, Lowary TL, Pinto BM. 2009. STD-NMR studies suggest that two acceptor substrates for GlfT2, a bifunctional galactofuranosyltransferase required for the biosynthesis of Mycobacterium tuberculosis arabinogalactan, compete for the same binding site. Chembiochem 10:2052-9.

35. Mayer M, Meyer B. 2001. Group epitope mapping by saturation transfer difference NMR to identify segments of a ligand in direct contact with a protein receptor. J Am Chem Soc 123:6108-17.

36. Zhang W, Olson JS, Phillips GN, Jr. 2005. Biophysical and kinetic characterization of HemAT, an aerotaxis receptor from Bacillus subtilis. Biophys J 88:2801-14.

37. Zhang W, Phillips GN, Jr. 2003. Structure of the oxygen sensor in Bacillus subtilis: signal transduction of chemotaxis by control of symmetry. Structure 11:1097-110.

38. Angulo J, Enriquez-Navas PM, Nieto PM. 2010. Ligand-receptor binding affinities from saturation transfer difference (STD) NMR spectroscopy: the binding isotherm of STD initial growth rates. Chemistry 16:7803-12.

39. Ordal GW, Goldman DJ. 1975. Chemotaxis away from uncouplers of oxidative phosphorylation in Bacillus subtilis. Science 189:802-5.

40. Ordal GW, Villani DP. 1980. Action of uncouplers of oxidative phosphorylation as chemotactic repellents of Bacillus subtilis. J Gen Microbiol 118:471-8.

41. Ordal GW, Goldman DJ. 1976. Chemotactic repellents of Bacillus subtilis. J Mol Biol 100:103-8.

42. Bi S, Jin F, Sourjik V. 2018. Inverted signaling by bacterial chemotaxis receptors. Nat Commun 9:2927.

43. Rico-Jimenez M, Munoz-Martinez F, Garcia-Fontana C, Fernandez M, Morel B, Ortega A, Ramos JL, Krell T. 2013. Paralogous chemoreceptors mediate chemotaxis towards 
protein amino acids and the non-protein amino acid gamma-aminobutyrate (GABA). Mol Microbiol 88:1230-43.

650

651

652

653

654

655

656

657

658

659

660

661

662

663

664

665

666

667

668

669

670

671

44. Parkinson JS. 2010. Signaling mechanisms of HAMP domains in chemoreceptors and sensor kinases. Annu Rev Microbiol 64:101-22.

45. Swain KE, Gonzalez MA, Falke JJ. 2009. Engineered socket study of signaling through a four-helix bundle: evidence for a yin-yang mechanism in the kinase control module of the aspartate receptor. Biochemistry 48:9266-77.

46. Zhou Q, Ames P, Parkinson JS. 2011. Biphasic control logic of HAMP domain signalling in the Escherichia coli serine chemoreceptor. Mol Microbiol 80:596-611.

47. Bartelli NL, Hazelbauer GL. 2016. Bacterial Chemoreceptor Dynamics: Helical Stability in the Cytoplasmic Domain Varies with Functional Segment and Adaptational Modification. J Mol Biol 428:3789-804.

48. Samanta D, Borbat PP, Dzikovski B, Freed JH, Crane BR. 2015. Bacterial chemoreceptor dynamics correlate with activity state and are coupled over long distances. Proc Natl Acad Sci U S A 112:2455-60.

49. Bartelli NL, Hazelbauer GL. 2015. Differential backbone dynamics of companion helices in the extended helical coiled-coil domain of a bacterial chemoreceptor. Protein Sci 24:1764-76.

50. Li X, Eyles SJ, Thompson LK. 2019. Hydrogen exchange of chemoreceptors in functional complexes suggests protein stabilization mediates long-range allosteric coupling. J Biol Chem 294:16062-16079.

51. Kashefi M, Thompson LK. 2017. Signaling-Related Mobility Changes in Bacterial Chemotaxis Receptors Revealed by Solid-State NMR. J Phys Chem B 121:8693-8705.

52. Yang W, Cassidy CK, Ames P, Diebolder CA, Schulten K, Luthey-Schulten Z, Parkinson JS, Briegel A. 2019. In Situ Conformational Changes of the Escherichia coli Serine Chemoreceptor in Different Signaling States. mBio 10. 
674 53. Stalla D, Akkaladevi N, White TA, Hazelbauer GL. 2019. Spatial Restrictions in

675

676

677

678

679

680

681

682

683

684

685

686

687

688

689

690

691

692

693

694

695

696

697

698

699

Chemotaxis Signaling Arrays: A Role for Chemoreceptor Flexible Hinges across Bacterial Diversity. Int J Mol Sci 20.

54. Kristich CJ, Glekas GD, Ordal GW. 2003. The conserved cytoplasmic module of the transmembrane chemoreceptor $\mathrm{McpC}$ mediates carbohydrate chemotaxis in Bacillus subtilis. Mol Microbiol 47:1353-66.

55. Yamamoto K, Imae Y. 1993. Cloning and characterization of the Salmonella typhimurium-specific chemoreceptor Tcp for taxis to citrate and from phenol. Proc Natl Acad Sci U S A 90:217-21.

56. Yamamoto K, Macnab RM, Imae Y. 1990. Repellent response functions of the Trg and Tap chemoreceptors of Escherichia coli. J Bacteriol 172:383-8.

57. Yang J, Chawla R, Rhee KY, Gupta R, Manson MD, Jayaraman A, Lele PP. 2020. Biphasic chemotaxis of Escherichia coli to the microbiota metabolite indole. Proc Natl Acad Sci U S A 117:6114-6120.

58. Anku WW, Mamo MA, Govender PP. 2017. Phenolic Compounds in Water: Sources, Reactivity, Toxicity and Treatment Methods, Phenolic Compounds - Natural Sources, Importance and Applications doi:10.5772/66927.

59. Mandal SM, Chakraborty D, Dey S. 2010. Phenolic acids act as signaling molecules in plant-microbe symbioses. Plant Signal Behav 5:359-68.

60. Bhattacharya A, Sood P, Citovsky V. 2010. The roles of plant phenolics in defence and communication during Agrobacterium and Rhizobium infection. Mol Plant Pathol 11:70519.

61. Scharf BE, Hynes MF, Alexandre GM. 2016. Chemotaxis signaling systems in model beneficial plant-bacteria associations. Plant Mol Biol 90:549-59.

62. Hashem A, Tabassum B, Fathi Abd Allah E. 2019. Bacillus subtilis: A plant-growth promoting rhizobacterium that also impacts biotic stress. Saudi J Biol Sci 26:1291-1297. 
700

701

702

703

704

705

706

707

708

709

710

711

712

713

714

715

716

717

718

719

720

721

722

723

724

725

63. Bacilio-Jiménez M, Aguilar-Flores S, Ventura-Zapata E, Pérez-Campos E, Bouquelet S, Zenteno E. 2003. Chemical characterization of root exudates from rice (Oryza sativa) and their effects on the chemotactic response of endophytic bacteria. Plant and Soil 249:271-277.

64. Allard-Massicotte R, Tessier L, Lecuyer F, Lakshmanan V, Lucier JF, Garneau D, Caudwell L, Vlamakis H, Bais HP, Beauregard PB. 2016. Bacillus subtilis Early Colonization of Arabidopsis thaliana Roots Involves Multiple Chemotaxis Receptors. mBio 7.

65. Ghosh S, Kebaara BW, Atkin AL, Nickerson KW. 2008. Regulation of aromatic alcohol production in Candida albicans. Appl Environ Microbiol 74:7211-8.

66. Hogan DA. 2006. Quorum sensing: alcohols in a social situation. Curr Biol 16:R457-8.

67. Achkar J, Xian M, Zhao H, Frost JW. 2005. Biosynthesis of phloroglucinol. J Am Chem Soc 127:5332-3.

68. Muller S, Strack SN, Hoefler BC, Straight PD, Kearns DB, Kirby JR. 2014. Bacillaene and sporulation protect Bacillus subtilis from predation by Myxococcus xanthus. Appl Environ Microbiol 80:5603-10.

69. Stein T. 2005. Bacillus subtilis antibiotics: structures, syntheses and specific functions. Mol Microbiol 56:845-57.

70. Desmyttere H, Deweer C, Muchembled J, Sahmer K, Jacquin J, Coutte F, Jacques P. 2019. Antifungal Activities of Bacillus subtilis Lipopeptides to Two Venturia inaequalis Strains Possessing Different Tebuconazole Sensitivity. Front Microbiol 10:2327.

71. Guha Thakurta S, Aakula M, Chakrabarty J, Dutta S. 2018. Bioremediation of phenol from synthetic and real wastewater using Leptolyngbya $\mathrm{sp} .:$ a comparison and assessment of lipid production. 3 Biotech 8:206.

72. Pandey G, Jain RK. 2002. Bacterial chemotaxis toward environmental pollutants: role in bioremediation. Appl Environ Microbiol 68:5789-95. 
73. Ahmad F, Zhu D, Sun J. 2020. Bacterial chemotaxis: a way forward to aromatic compounds biodegradation. Environmental Sciences Europe 32.

74. Ullah AH, Ordal GW. 1981. In vivo and in vitro chemotactic methylation in Bacillus subtilis. J Bacteriol 145:958-65.

75. Gibson DG, Glass JI, Lartigue C, Noskov VN, Chuang RY, Algire MA, Benders GA, Montague MG, Ma L, Moodie MM, Merryman C, Vashee S, Krishnakumar R, AssadGarcia N, Andrews-Pfannkoch C, Denisova EA, Young L, Qi ZQ, Segall-Shapiro TH, Calvey CH, Parmar PP, Hutchison CA, 3rd, Smith HO, Venter JC. 2010. Creation of a bacterial cell controlled by a chemically synthesized genome. Science 329:52-6.

76. Anagnostopoulos C, Spizizen J. 1961. Requirements for Transformation in Bacillus Subtilis. J Bacteriol 81:741-6.

77. Lepre CA, Moore JM, Peng JW. 2004. Theory and applications of NMR-based screening in pharmaceutical research. Chem Rev 104:3641-76.

78. Gumerov VM, Ortega DR, Adebali O, Ulrich LE, Zhulin IB. 2020. MiST 3.0: an updated microbial signal transduction database with an emphasis on chemosensory systems. Nucleic Acids Res 48:D459-D464.

79. Gumerov VM, Zhulin IB. 2020. TREND: a platform for exploring protein function in prokaryotes based on phylogenetic, domain architecture and gene neighborhood analyses. Nucleic Acids Res 48:W72-W76.

80. Katoh K, Rozewicki J, Yamada KD. 2019. MAFFT online service: multiple sequence alignment, interactive sequence choice and visualization. Brief Bioinform 20:1160-1166.

81. Price MN, Dehal PS, Arkin AP. 2010. FastTree 2--approximately maximum-likelihood trees for large alignments. PLoS One 5:e9490.

82. Eddy SR. 2011. Accelerated Profile HMM Searches. PLoS Comput Biol 7:e1002195.

83. Webb B, Sali A. 2016. Comparative Protein Structure Modeling Using MODELLER. Curr Protoc Bioinformatics 54:5 6 1-5637. 
84. Park SY, Borbat PP, Gonzalez-Bonet G, Bhatnagar J, Pollard AM, Freed JH, Bilwes AM, Crane BR. 2006. Reconstruction of the chemotaxis receptor-kinase assembly. Nat Struct Mol Biol 13:400-7.

85. Krivov GG, Shapovalov MV, Dunbrack RL, Jr. 2009. Improved prediction of protein sidechain conformations with SCWRL4. Proteins 77:778-95.

86. Krieger E, Joo K, Lee J, Lee J, Raman S, Thompson J, Tyka M, Baker D, Karplus K. 2009. Improving physical realism, stereochemistry, and side-chain accuracy in homology modeling: Four approaches that performed well in CASP8. Proteins 77 Suppl 9:114-22.

87. Kim S, Chen J, Cheng T, Gindulyte A, He J, He S, Li Q, Shoemaker BA, Thiessen PA, Yu B, Zaslavsky L, Zhang J, Bolton EE. 2021. PubChem in 2021: new data content and improved web interfaces. Nucleic Acids Res 49:D1388-D1395.

88. Trott O, Olson AJ. 2010. AutoDock Vina: improving the speed and accuracy of docking with a new scoring function, efficient optimization, and multithreading. J Comput Chem $31: 455-61$

89. Morris GM, Huey R, Lindstrom W, Sanner MF, Belew RK, Goodsell DS, Olson AJ. 2009. AutoDock4 and AutoDockTools4: Automated docking with selective receptor flexibility. J Comput Chem 30:2785-91.

90. Kristich CJ, Ordal GW. 2002. Bacillus subtilis CheD is a chemoreceptor modification enzyme required for chemotaxis. J Biol Chem 277:25356-62. 
bioRxiv preprint doi: https://doi.org/10.1101/2021.08.31.458471. this version posted September 1, 2021. The copyright holder for this preprint (which was not certified by peer review) is the author/funder, who has granted bioRxiv a license to display the preprint in perpetuity. It is made available under aCC-BY-NC-ND 4.0 International license.

TABLE 1. STD Amplification factors for phenol-protein interactions

\begin{tabular}{cccc}
\hline Protein & $\mathbf{H}(\mathbf{2})$ Meta proton & $\mathbf{H ( 3 )}$ Para proton & $\mathbf{H ( 1 )}$ Ortho proton \\
\hline McpA $_{C}$ & 11.09 & 13.69 & 11.61 \\
McpA $_{S}$ & 3.52 & 5.54 & 3.72 \\
McpC $_{C}$ & 3.11 & 4.15 & 2.89 \\
McpC $_{S}$ & 0.82 & 1.33 & 1.28 \\
HemAT $_{C}$ & 23.85 & 26.90 & 24.29 \\
HemAT $_{S}$ & 17.41 & 19.50 & 15.87 \\
McpB $_{C}$ & 3.64 & 4.02 & 3.22 \\
\hline
\end{tabular}

774

775 
TABLE 2. Strains used in this study.

\begin{tabular}{|c|c|c|}
\hline Strain & Relevant genotype or description & Reference \\
\hline 5-alpha & E. coli cloning host & $\begin{array}{l}\text { New England } \\
\text { Biolabs }\end{array}$ \\
\hline BL21(DE3) & E. coli protease deficient expression host & Novagen \\
\hline Ol1085 & trpF7 hisH2 metC133 che $^{+}$ & $(74)$ \\
\hline PTS324 & $\triangle m c p A$ & (19) \\
\hline PTS325 & $\Delta t / p A$ & (19) \\
\hline PTS334 & $\Delta m c p A \Delta t / p A$ & (19) \\
\hline Ol3545 & $\Delta 10 \mathrm{mcp} ; \mathrm{Erm}^{R}, \mathrm{Cm}^{R}, \mathrm{Kan}^{R}, \mathrm{che+}$ & (24) \\
\hline Ol3921 & OI3545 amyE5720::mcpA; Spc ${ }^{R}$ & (90) \\
\hline Ol3605 & OI3545 amyE5720::mcpB; Spc ${ }^{R}$ & (54) \\
\hline Ol3974 & OI3545 amyE5720::mcpC; Spc ${ }^{R}$ & (54) \\
\hline Ol4474 & OI3545 amyE5720::t/pA; Spc ${ }^{R}$ & (19) \\
\hline Ol4475 & OI3545 amyE5720::t/pB; Spc ${ }^{R}$ & (19) \\
\hline O14483 & OI3545 amyE5720::t/pC; Spc ${ }^{R}$ & (19) \\
\hline Ol4476 & OI3545 amyE5720::yfmS; Spc ${ }^{R}$ & (19) \\
\hline O14477 & OI3545 amyE5720::yvaQ; Spc ${ }^{R}$ & (19) \\
\hline Ol4482 & OI3545 amyE5720::hemAT; Spc ${ }^{R}$ & (19) \\
\hline Ol4479 & OI3545 amyE5720::yoaH; Spc ${ }^{R}$ & (19) \\
\hline GBS141 & OI3545 amyE5720::P $P_{m c p A}-m c p B ; S p c^{R}$ & This work \\
\hline GBS041 & OI3545 amyE5720::P $P_{m c p A}-t / p A ; S p c^{R}$ & This work \\
\hline PTS155 & $\begin{array}{l}\text { OI3545 amyE5720::P } P_{m c p A}-m c p A[M 1-L 44] m c p B[D 45-T 267] \\
m c p A[M 267-E 661] ; S^{R} c^{R}\end{array}$ & This work \\
\hline PTS157 & $\begin{array}{l}\text { OI3545 amyE5720::P } P_{m c p A}-m c p B[M 1-Q 359] \text { mcpA[D359-E661]; } \\
\text { Spc }^{R}\end{array}$ & This work \\
\hline GBS119 & $\begin{array}{l}\text { OI3545 amyE5720::P } P_{m c p A}-m c p B[M 1-N 397] \text { mcpA[E397-E661]; } \\
\text { Spc }\end{array}$ & This work \\
\hline GBS118 & $\begin{array}{l}\text { OI3545 amyE5720::P } P_{m c p A}-m c p B[M 1-1433] \text { mcpA[Q433-E661]; } \\
\text { Spc }^{R}\end{array}$ & This work \\
\hline GBS208 & $\begin{array}{l}\text { OI3545 amyE5720::P } P_{m c p A}-m c p A[M 1-Q 358] ~ m c p B[D 359-E 662] ; \\
\text { Spc }\end{array}$ & This work \\
\hline
\end{tabular}


TABLE 3. Plasmids used in this study.

\begin{tabular}{|c|c|c|}
\hline Plasmid & Description & Reference \\
\hline $\begin{array}{l}\text { pET28a (+) } \\
\text { pAIN750 }\end{array}$ & $\begin{array}{l}\text { His-tagged cloning vector for protein purification; } \mathrm{Kan}^{R} \\
\text { B. subtilis empty vector for integration at amyE; } \mathrm{Amp}^{R} \text {, } \\
\text { Spc }^{R}\end{array}$ & $\begin{array}{l}\text { Novagen } \\
(90)\end{array}$ \\
\hline pAIN750mсpA & pAIN750::mcpA & $(54)$ \\
\hline pAIN750mсpB & pAIN750::mcpB & (54) \\
\hline рРT059 & $\begin{array}{l}\text { pAIN750::mcpA[M1-L44] mсpB[D45-T267] } \\
m c p A[M 267-E 661]\end{array}$ & This work \\
\hline рРТ086 & pAIN750::mсрA[M1-Q358] mсрB[D359-E662] & $(25)$ \\
\hline рPT061 & pAIN750::mcpB[M1-Q359] mсpA[D359-E661] & This work \\
\hline pGB43 & pAIN750::mcpB[M1-N397] mсpA[E397-E661] & $(25)$ \\
\hline pGB34 & pAIN750::mcpB[M1-I433] mcpA[Q433-E661] & (25) \\
\hline pGB131 & $\begin{array}{l}\text { 6xHis-N terminal McpB expression plasmid, } \\
\text { pET28(a)::mcpB } B_{C}\end{array}$ & This work \\
\hline pGB130 & $\begin{array}{l}6 x H i s-N \text { terminal McpA expression plasmid, } \\
\text { pET28(a)::mcp } A_{C}\end{array}$ & This work \\
\hline рPT021 & $\begin{array}{l}\text { 6xHis-C terminal McpA expression plasmid, } \\
\mathrm{pET} 28(\mathrm{a}):: m c p A_{S}\end{array}$ & This work \\
\hline pGB46 & $\begin{array}{l}\text { 6xHis- } \mathrm{N} \text { terminal HemAT expression plasmid, } \\
\text { pET28(a)::hemA } T_{C}\end{array}$ & (25) \\
\hline pSP03 & $\begin{array}{l}\text { 6xHis- } N \text { terminal HemAT expression plasmid, } \\
\text { pET28(a)::hemATs }\end{array}$ & $(25)$ \\
\hline
\end{tabular}


A

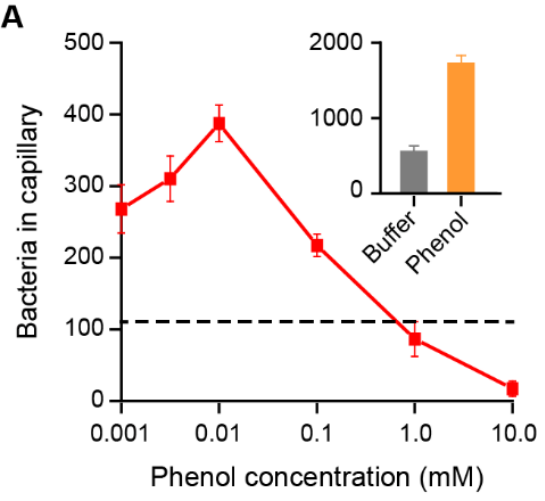

C

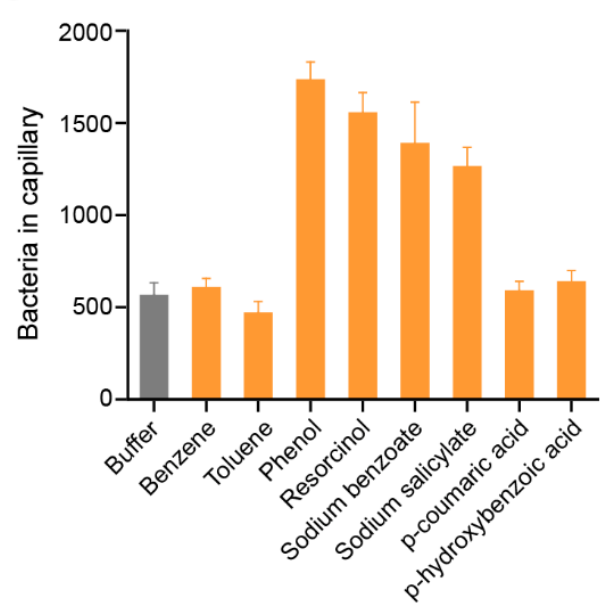

B

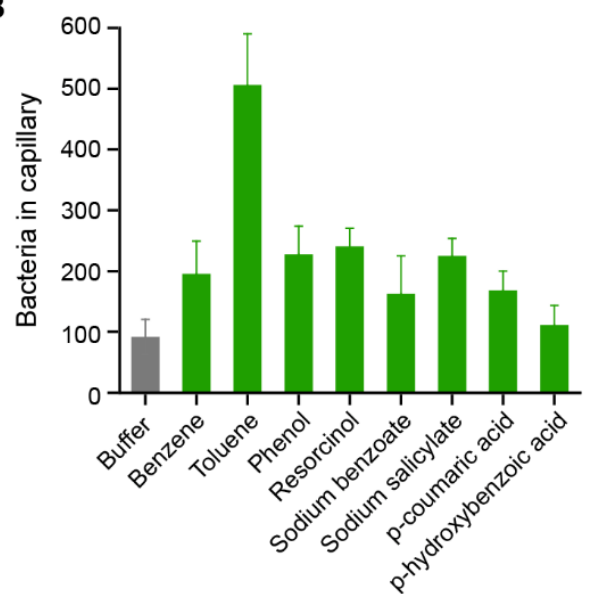

D

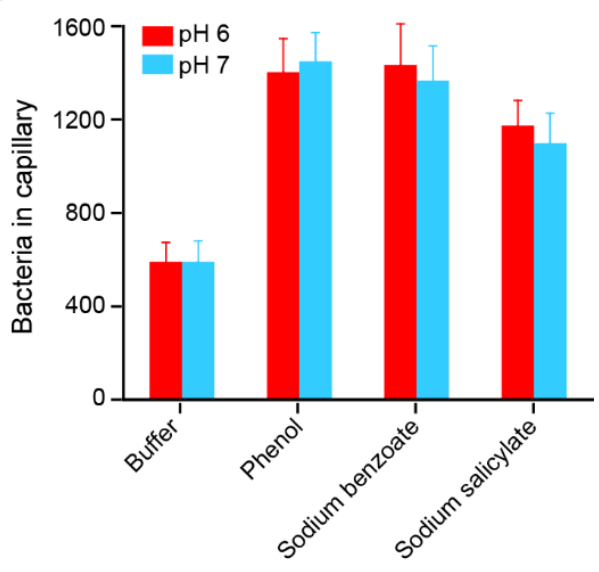

Figure 1. Attractant and repellent chemotaxis responses of wild-type $B$. subtilis towards

phenol and other aromatic compounds. (A) Dose-dependent response of the wild-type strain

to increasing concentrations of phenol measured using the attractant capillary assay. The dashed line indicates the base response to buffer control; inset shows the repellent response to

$7871 \mathrm{mM}$ phenol measured in the repellent capillary assay. (B) Attractant chemotaxis response of

788 the wild-type strain to $1 \mu \mathrm{M}$ aromatic compounds in the attractant capillary assay. (C) Repellent 789 chemotaxis response of the wild-type strain to $1 \mathrm{mM}$ aromatic compounds in the repellent 790 capillary assay. (D) Chemotaxis response of the wild-type strain to weak acids at neutral and $\mathrm{pH}$ 
bioRxiv preprint doi: https://doi org/10.1101/2021.08.31.458471: this version posted September 1, 2021. The copyright holder for this preprint

(which was not certified by peer review) is the author/funder, who has granted bioRxiv a license to display the preprint in perpetuity. It is made available under aCC-BY-NC-ND 4.0 International license.

7916.0 in the repellent capillary assay. Error bars indicate standard deviations obtained from three

792 biological replicates performed at separate days.

793 
A

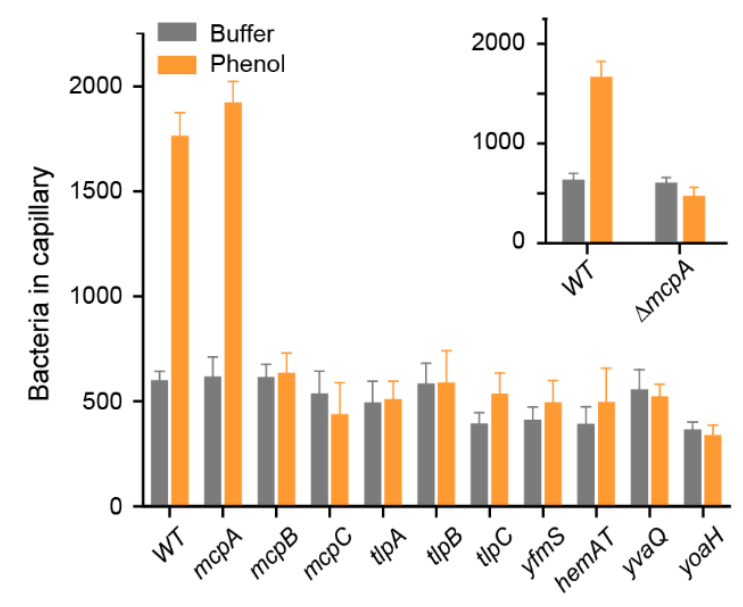

C

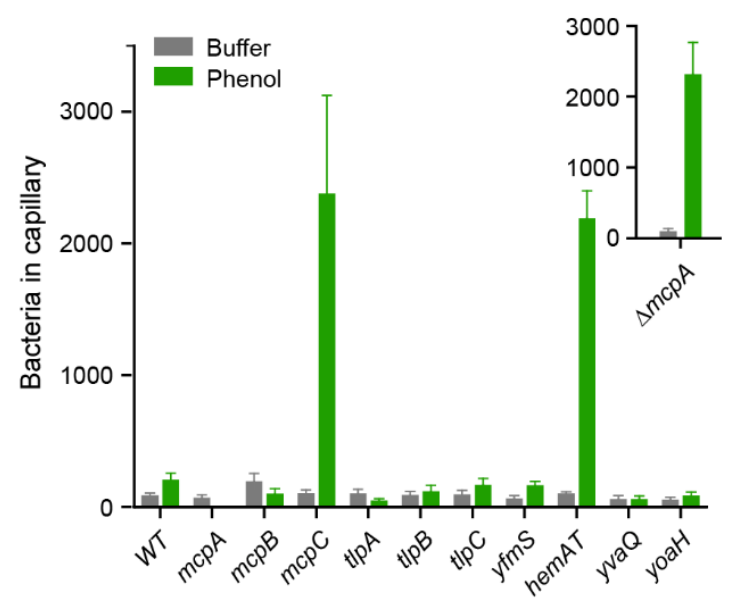

B

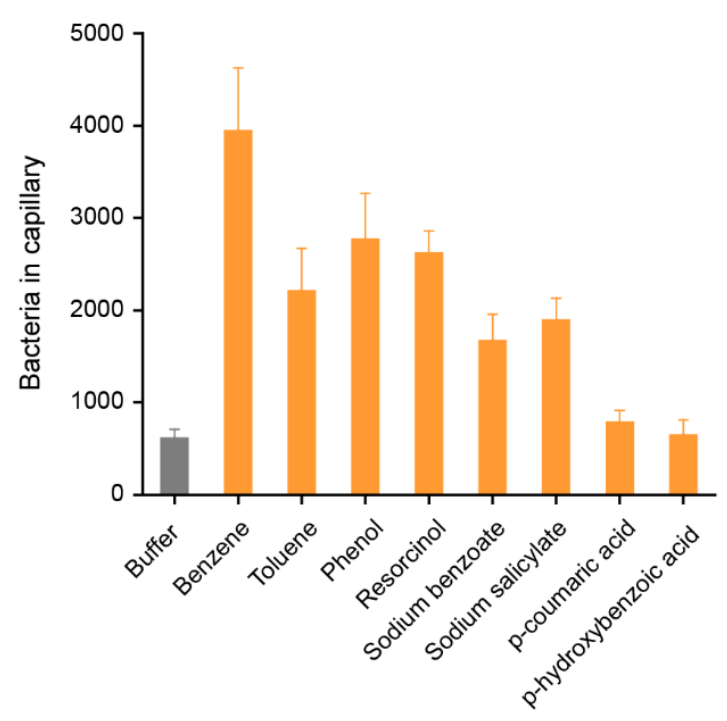

D

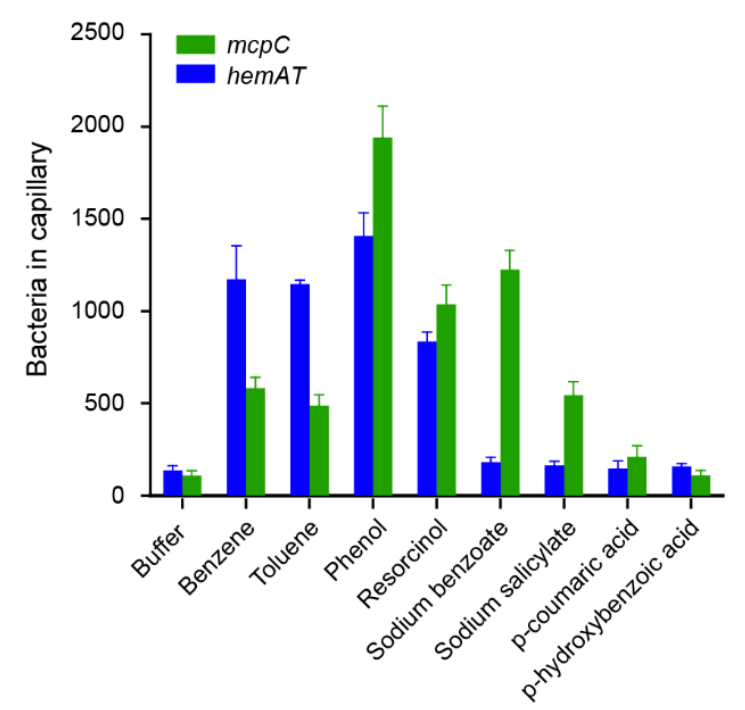

Figure 2. B. subtilis chemoreceptors involved in sensing phenol and other aromatic compounds as a repellent or an attractant. (A) Repellent chemotaxis responses of strains expressing single chemoreceptors to phenol measured in the repellent capillary assay; inset shows repellent chemotaxis response of a mutant lacking McpA chemoreceptor $(\Delta m c p A)$ to phenol. (B) Repellent chemotaxis responses of strains expressing McpA as their sole chemoreceptor to different aromatic compounds measured in the repellent capillary assay. (C) Attractant chemotaxis responses of strains expressing single chemoreceptors to phenol measured in the attractant capillary assay; inset shows attractant chemotaxis response of a 
803 mutant lacking McpA chemoreceptor $(\Delta m c p A)$ to phenol. (D) Attractant chemotaxis responses

804 of strains expressing McpC or HemAT as their sole chemoreceptors to different aromatic 805 compounds. Concentrations of chemoeffectors were set to $316 \mu \mathrm{M}$ in the ponds and $0.1 \mathrm{M}$ in

806 the capillaries for repellent and attractant capillary assays, respectively. Error bars indicate 807 standard deviations obtained from three biological replicates performed at separate days.

808 
A

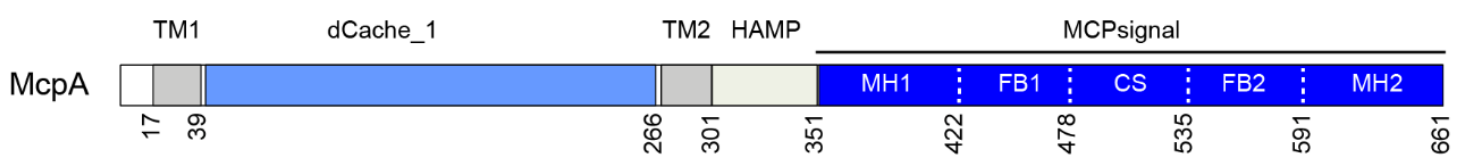

B

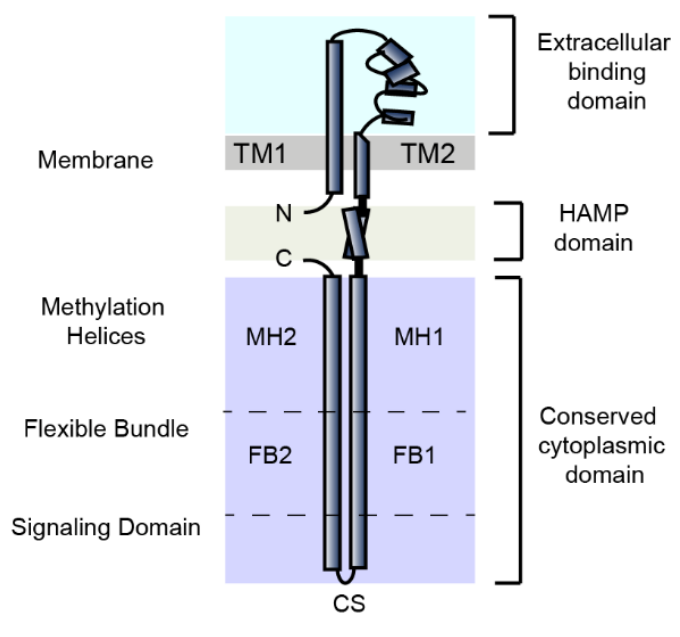

Receptor monomer
C

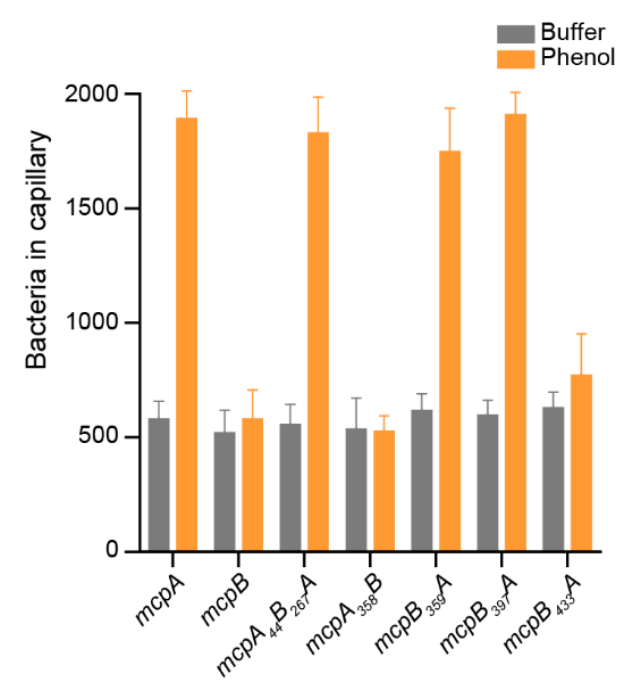

811 Domain structure of McpA. The chemoreceptor consists of an extracellular sensing domain

812 (dCACHE_1), two transmembrane helices (TM1 and TM2), followed by an intracellular HAMP

813 domain, and an intracellular signaling domain (MCPsignal). The signaling domain is comprised

814 of three subdomains known as the methylation helices $(\mathrm{MH})$, flexible bundle $(\mathrm{FB})$, and

815 conserved signaling tip (CS). (B) Cartoon structure of McpA chemoreceptor monomer. (C)

816 Repellent chemotaxis responses of strains expressing different chimeras between McpA and

$817 \mathrm{McpB}$ as their sole chemoreceptor to $316 \mu \mathrm{M}$ phenol measured in the repellent capillary assays.

818 Error bars indicate standard deviations obtained from three biological replicates performed at 819 separate days. 
A<smiles>Oc1ccccc1</smiles>

Phenol

B

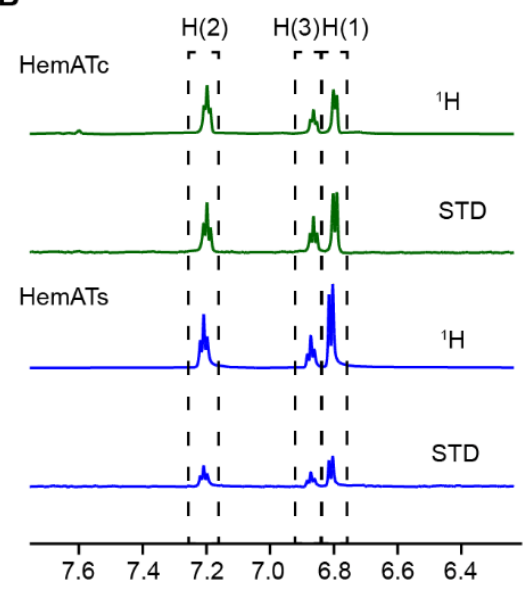

Chemical shift (ppm)
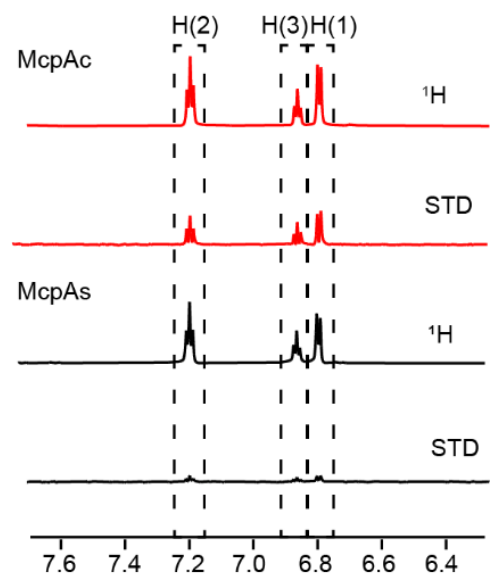

Chemical shift (ppm)

C

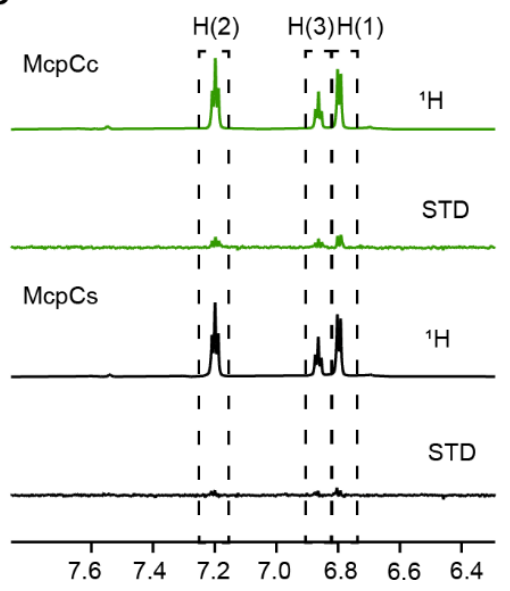

Chemical shift (ppm)

Figure 4. In-vitro characterization of binding between phenol and $B$. subtilis

823 chemoreceptors. (A) ${ }^{1} \mathrm{H}$ and STD-NMR spectra obtained from incubation of $20 \mu \mathrm{M}$ McpA

824 signaling (top) and sensing (bottom) domains with $2 \mathrm{mM}$ phenol. (B) ${ }^{1} \mathrm{H}$ and STD-NMR spectra

825 obtained from incubation of $20 \mu \mathrm{M}$ HemAT signaling (top) and sensing (bottom) domains with 2

$826 \mathrm{mM}$ phenol. (C) ${ }^{1} \mathrm{H}$ and STD-NMR spectra obtained from incubation of $20 \mu \mathrm{M}$ McpC signaling

827 (top) and sensing (bottom) domains with $2 \mathrm{mM}$ phenol. ${ }^{1} \mathrm{H}$ peaks for ortho, meta, and para

828 moieties of phenol are shown within dashed boxes. 
A

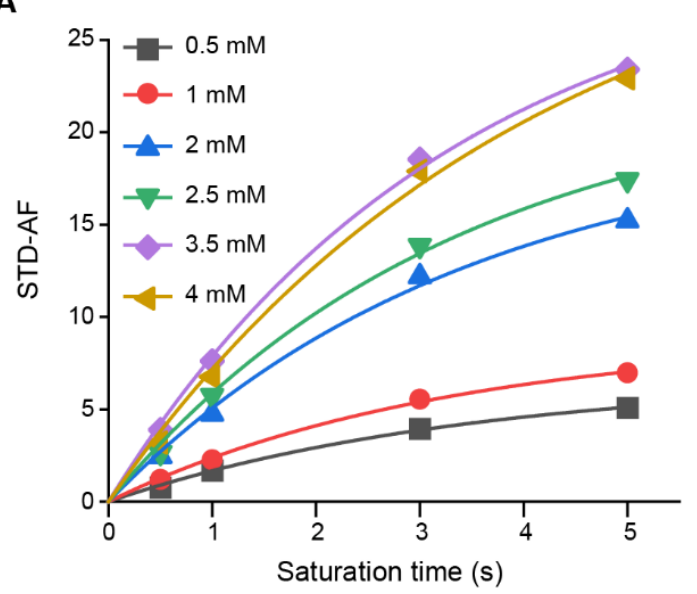

B

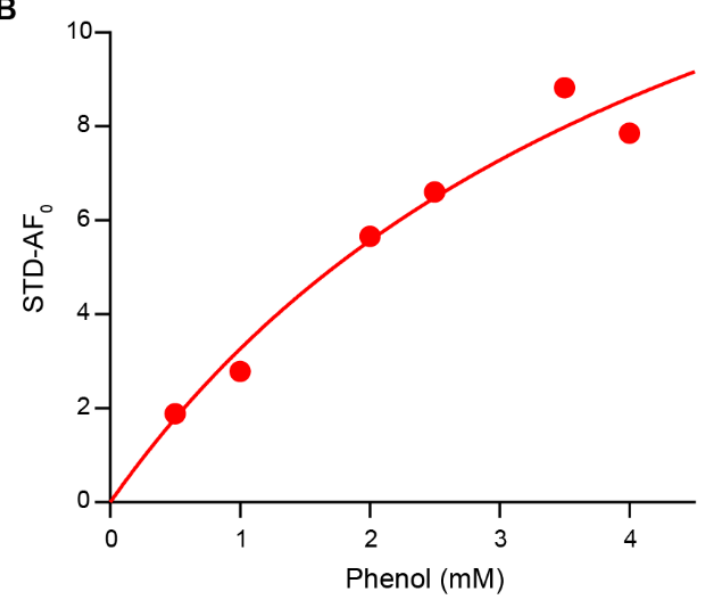

Figure 5. Estimation of dissociation constant $\left(\mathrm{K}_{\mathrm{d}}\right)$ of binding between the McpA signaling

832 domain and phenol using STD-NMR. (A) Time evolution of STD amplification factor (STD-AF)

833 values obtained from incubation of $20 \mu \mathrm{M}$ McpA signaling domain with different concentrations

834 of phenol $(0.5 \mathrm{mM}-4 \mathrm{mM})$. The initial slope $\left(S T D-A F_{0}\right)$ values were calculated from the fitted

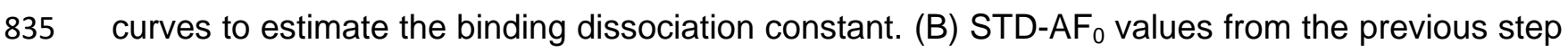

836 were fitted against different phenol concentrations to estimate the binding dissociation constant

837 using the Langmuir isotherm model $\left(S T D-A F_{0}=\frac{\alpha L}{L+K_{d}} ; \mathrm{K}_{\mathrm{d}}=4.8 \mathrm{mM}, \alpha=18.9, \mathrm{R}^{2}=0.98\right)$. 


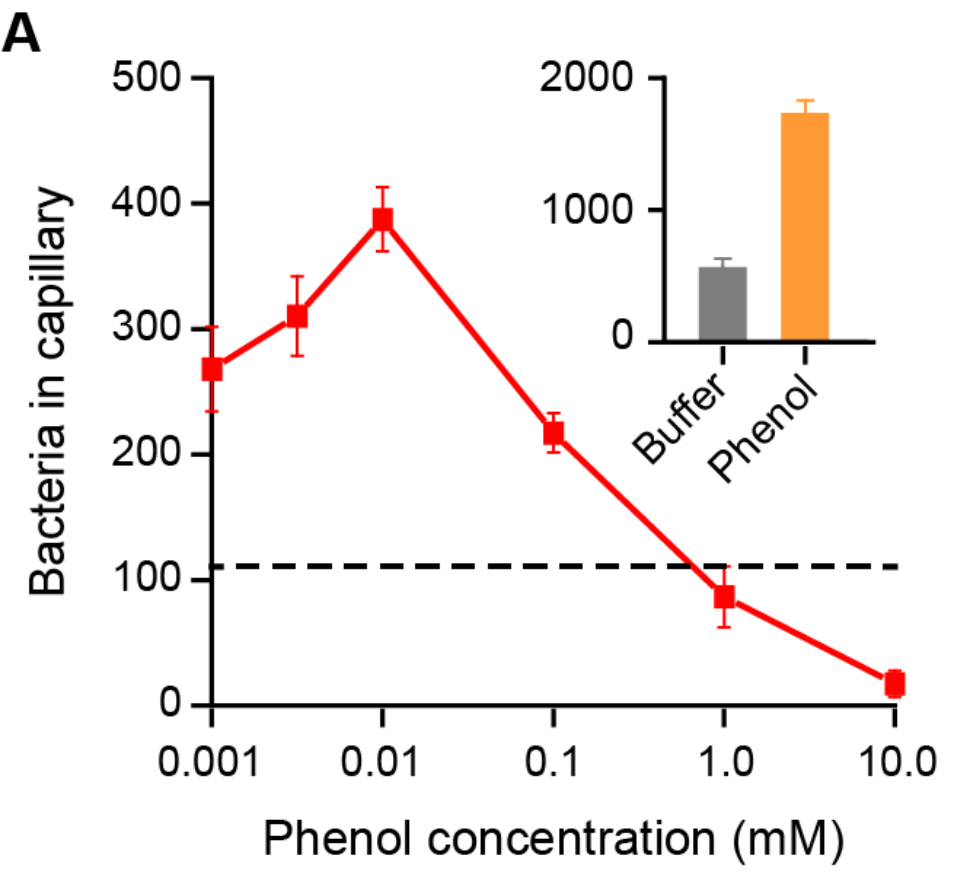

C

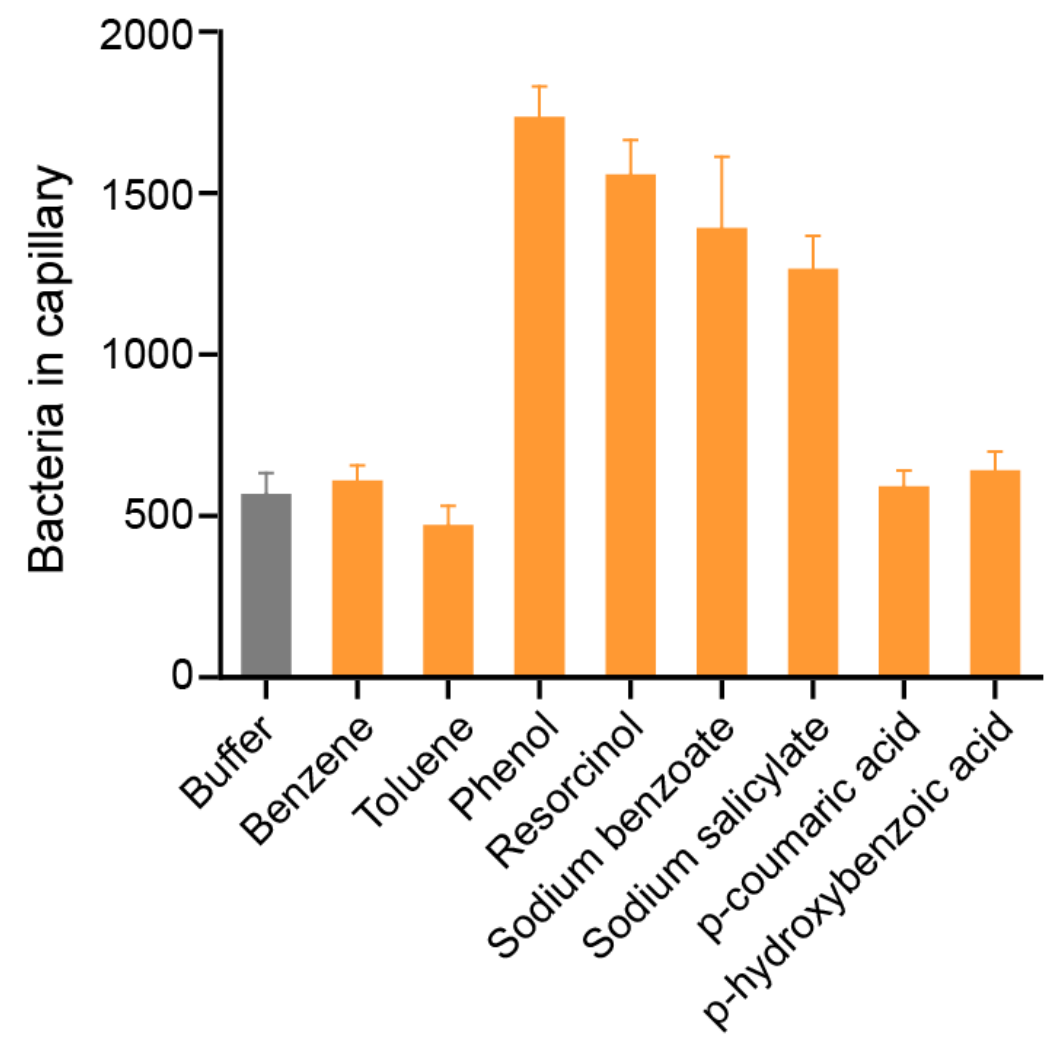

B
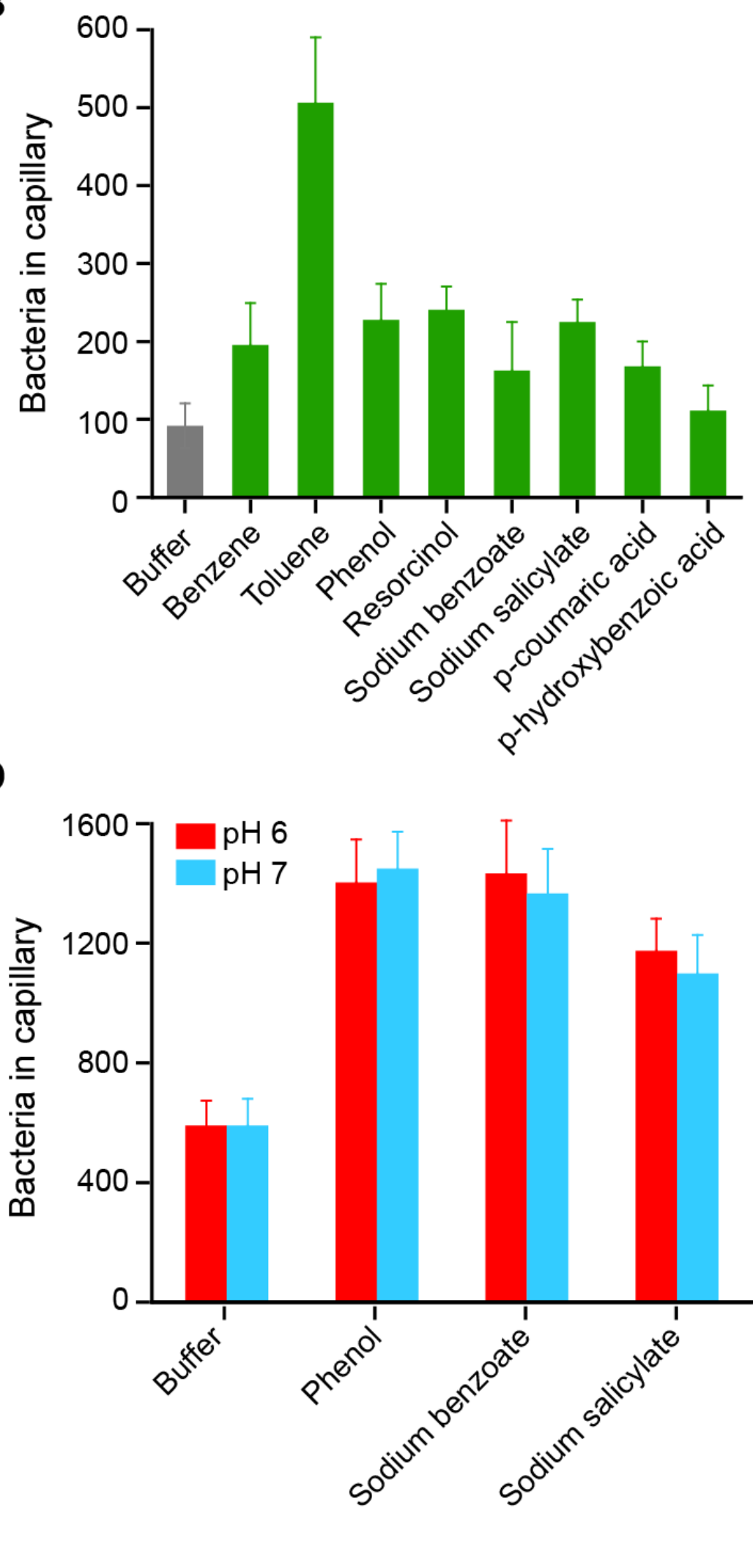
A

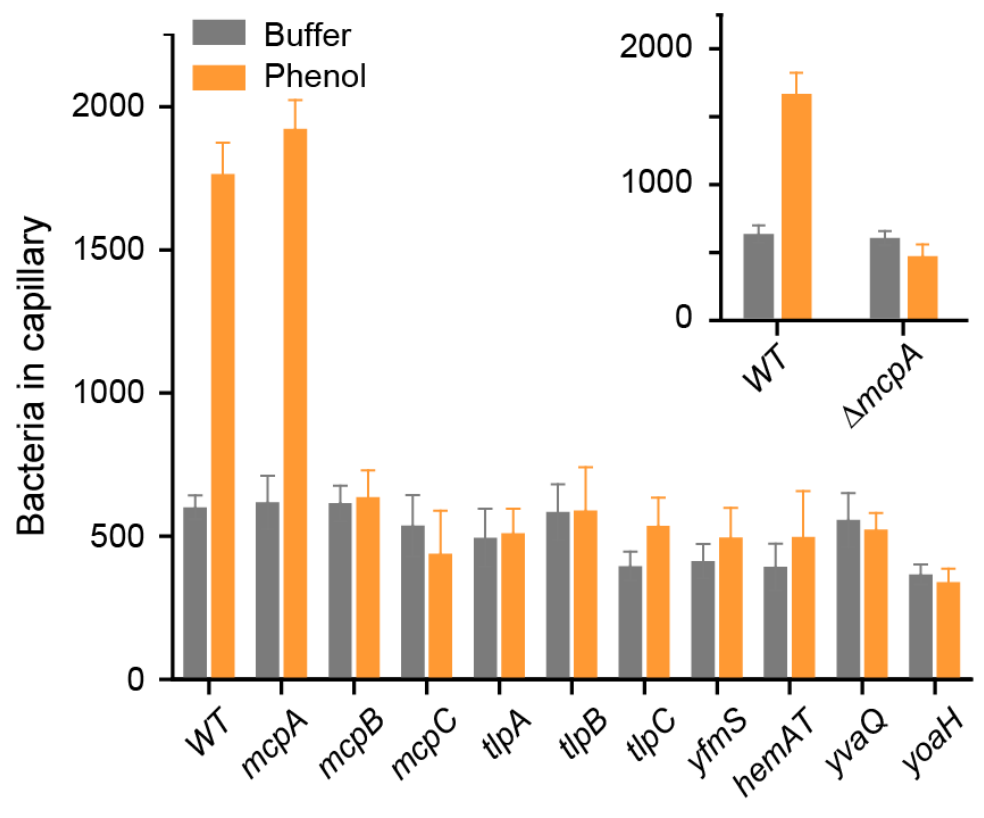

C

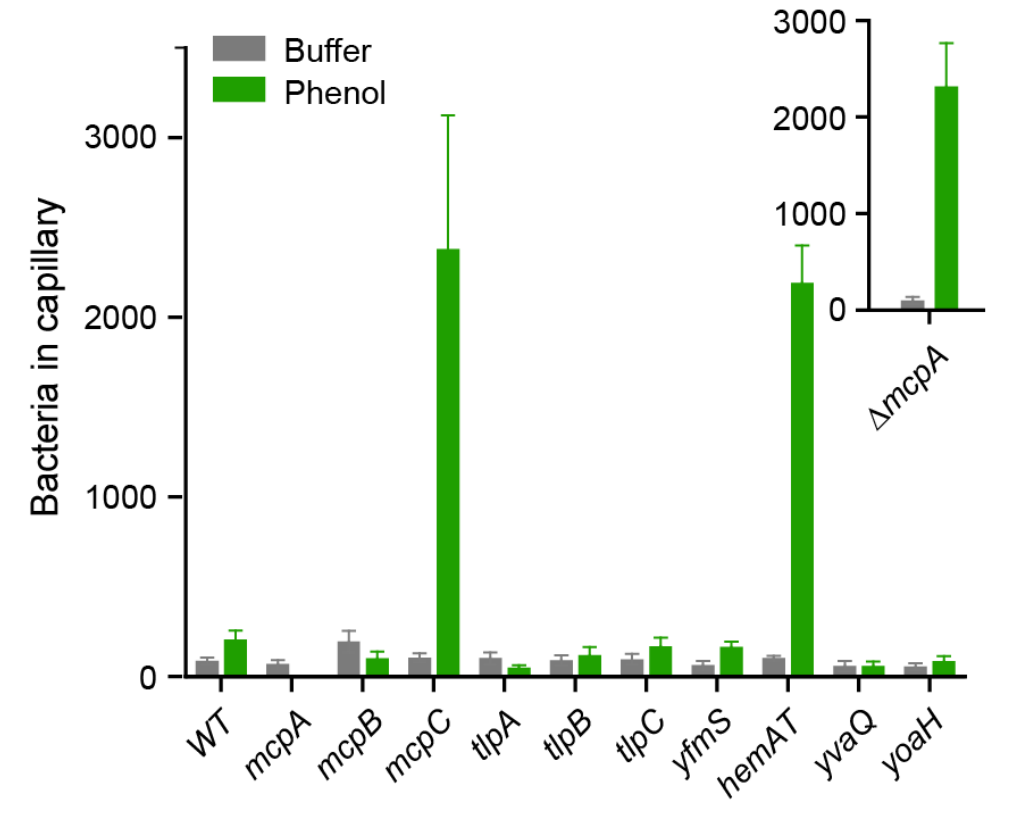

B

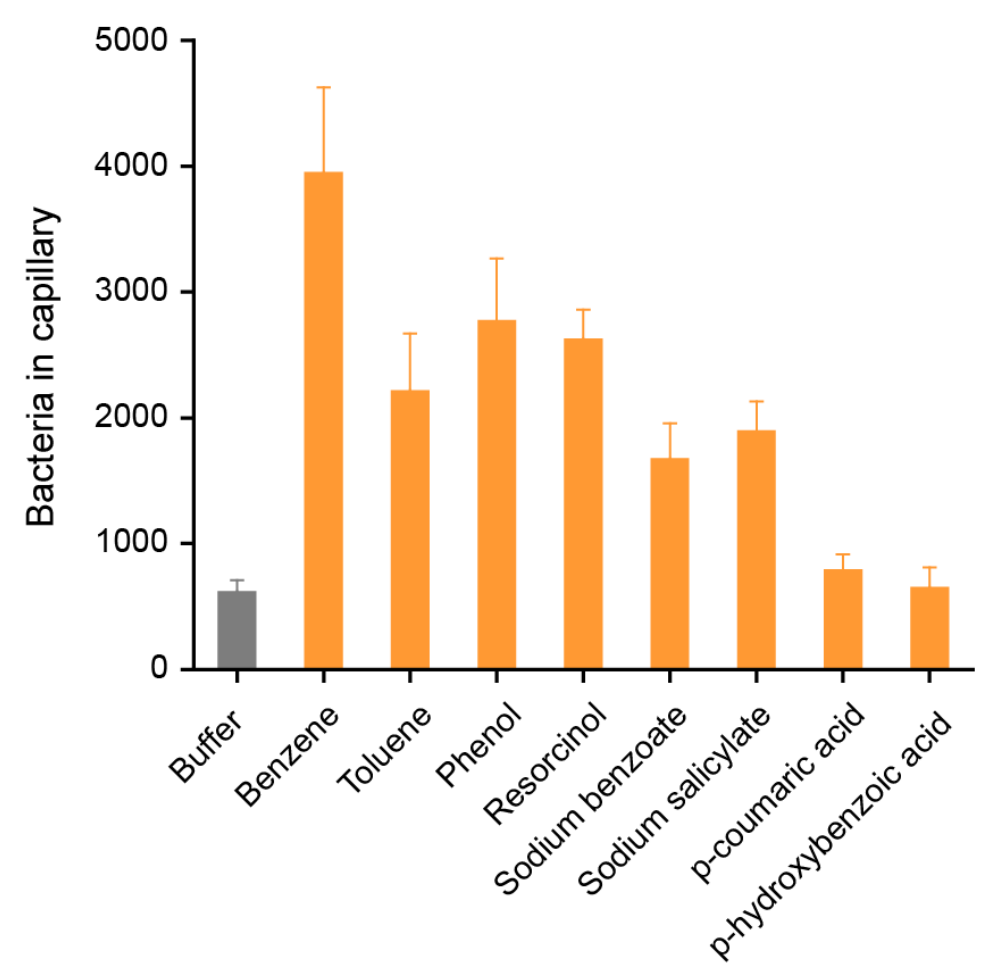

D

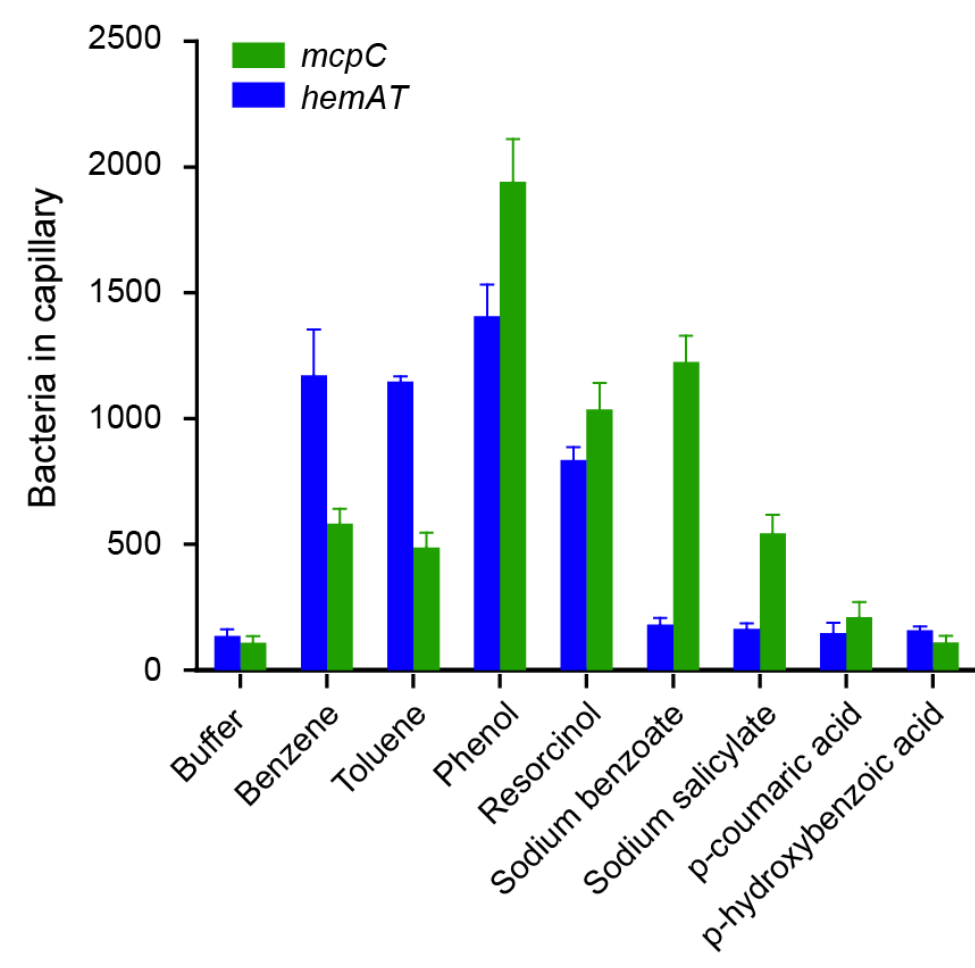


A

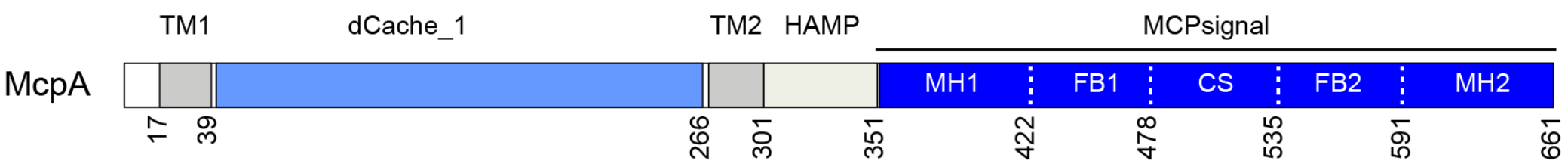

B

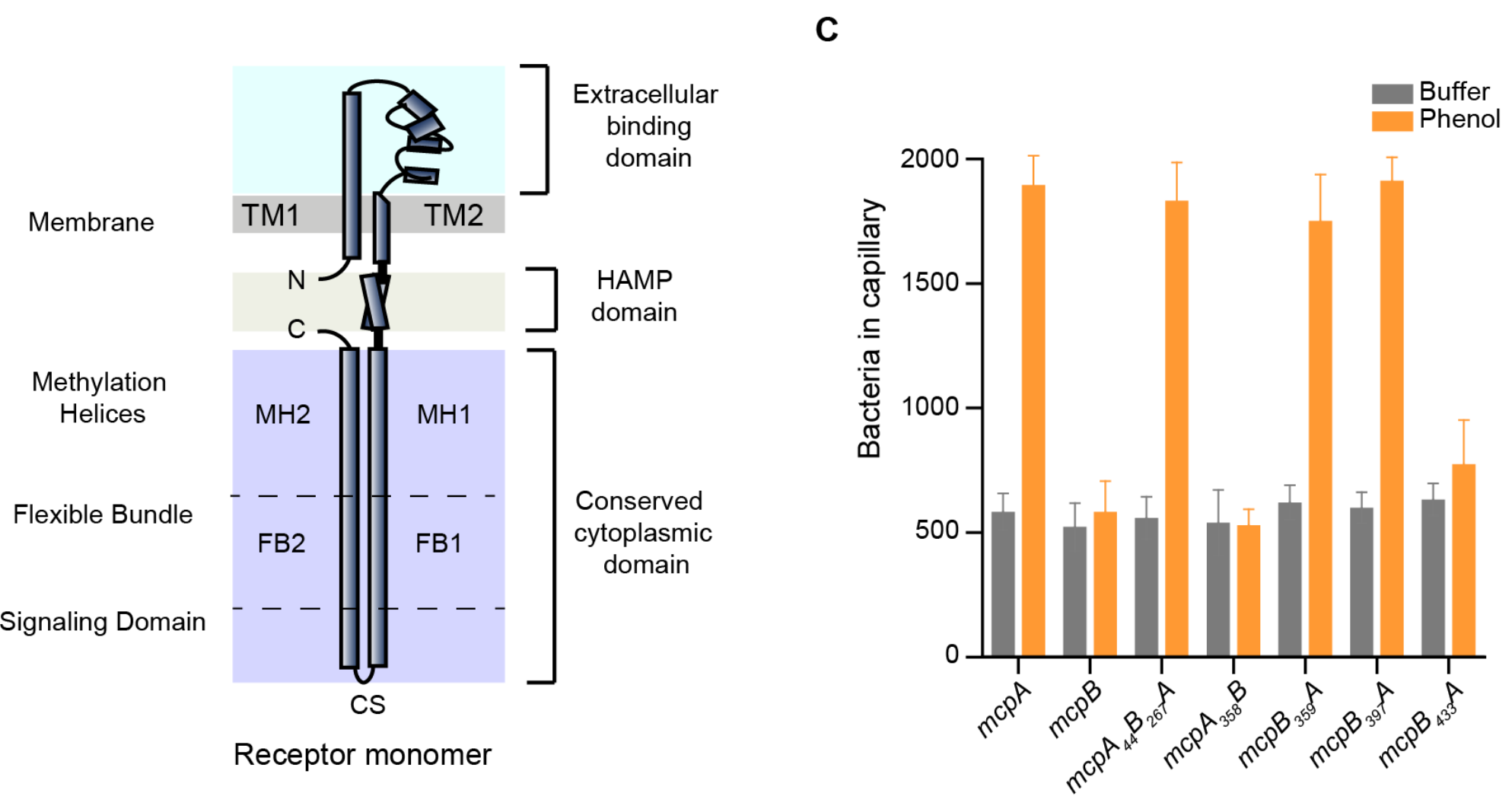


bioRxiv preprint doi: https://doi.org/10.1101/2021.08.31.458471; this version posted September 1, 2021. The copyright holder for this preprint (which was not certified by peer review) is the author/funder, who has granted bioRxiv a license to display the preprint in perpetuity. It is made

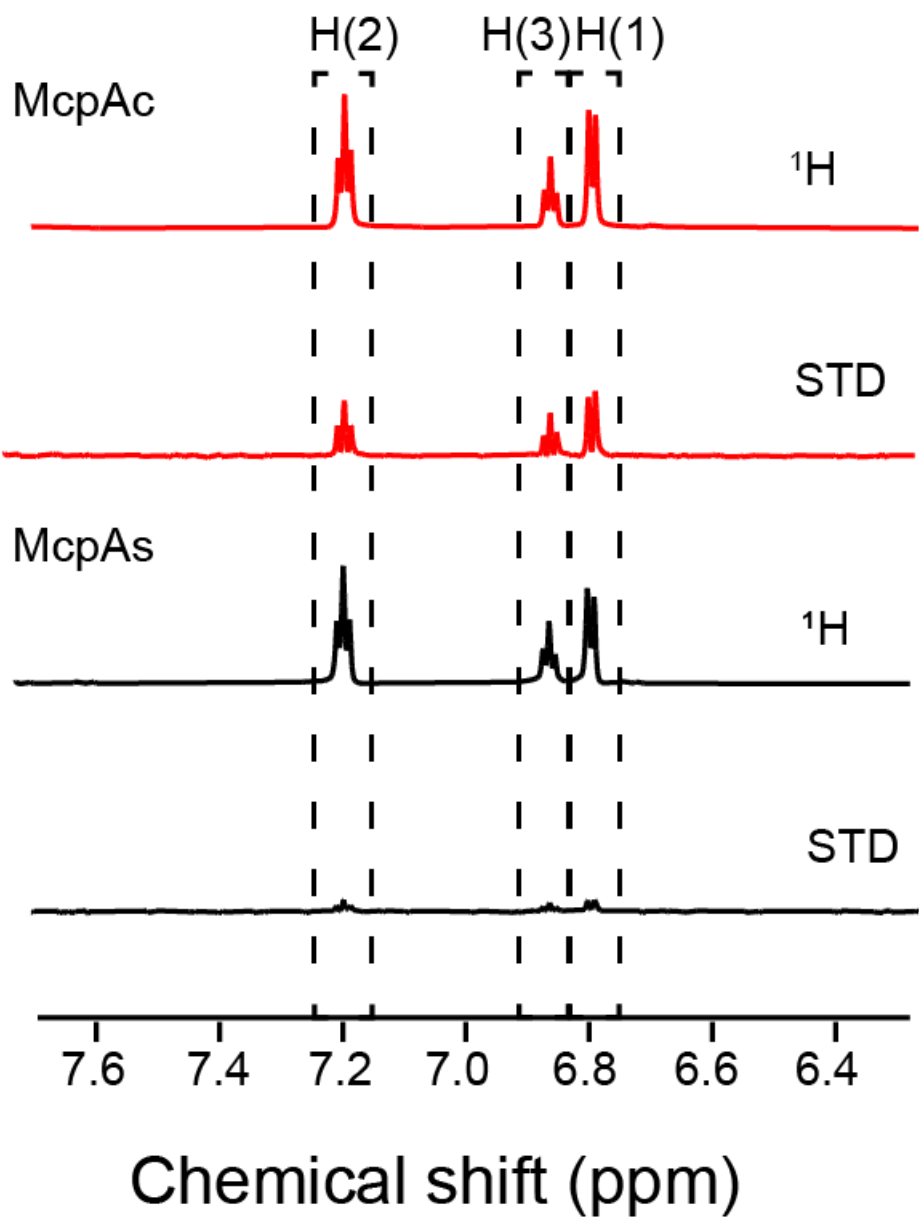

Phenol

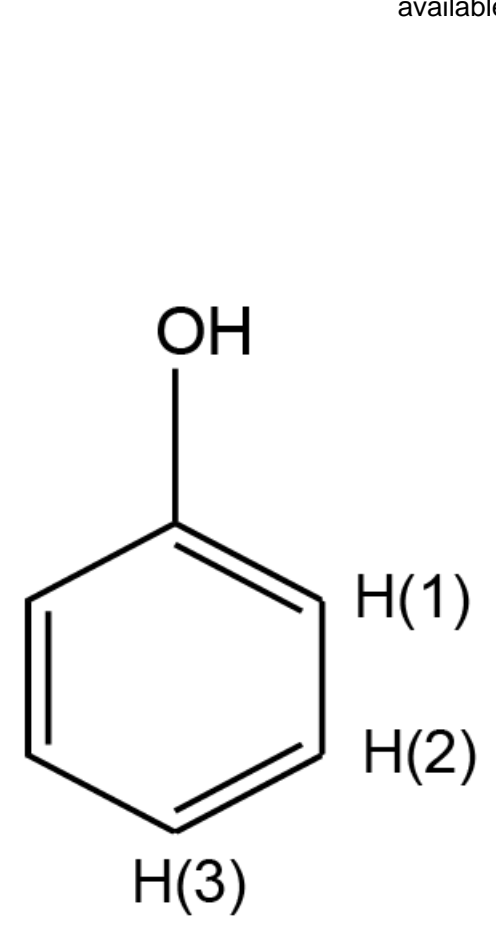

B

$\mathrm{H}(2) \quad \mathrm{H}(3) \mathrm{H}(1)$

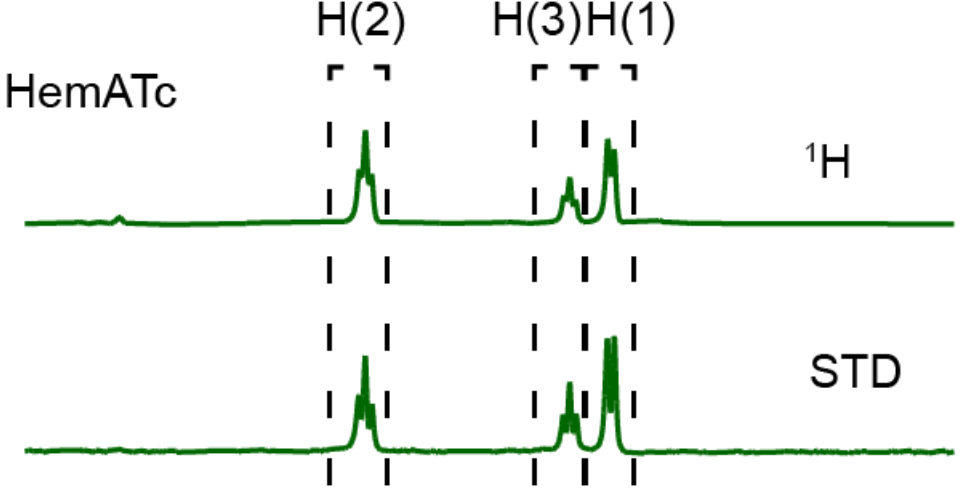

H

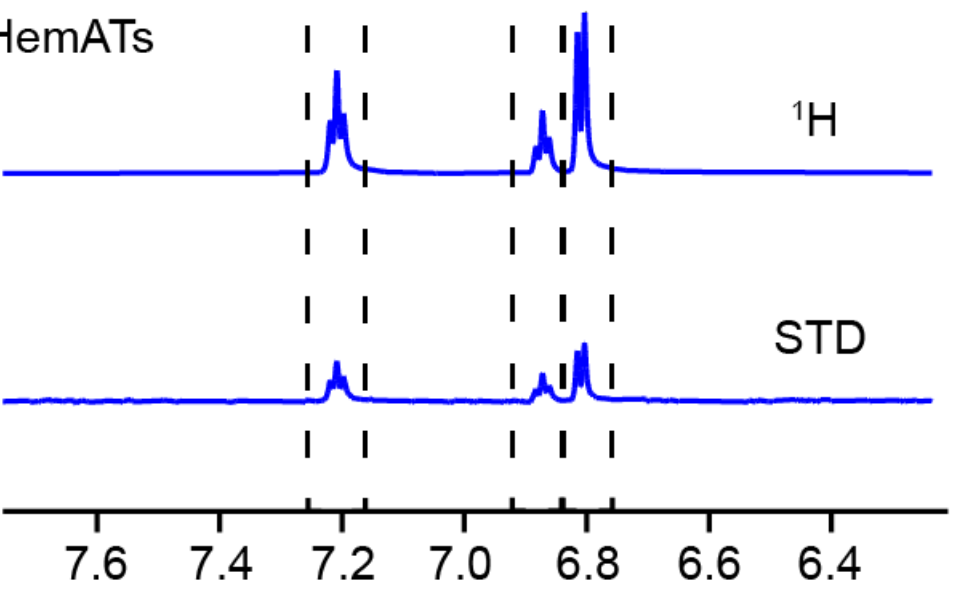

C

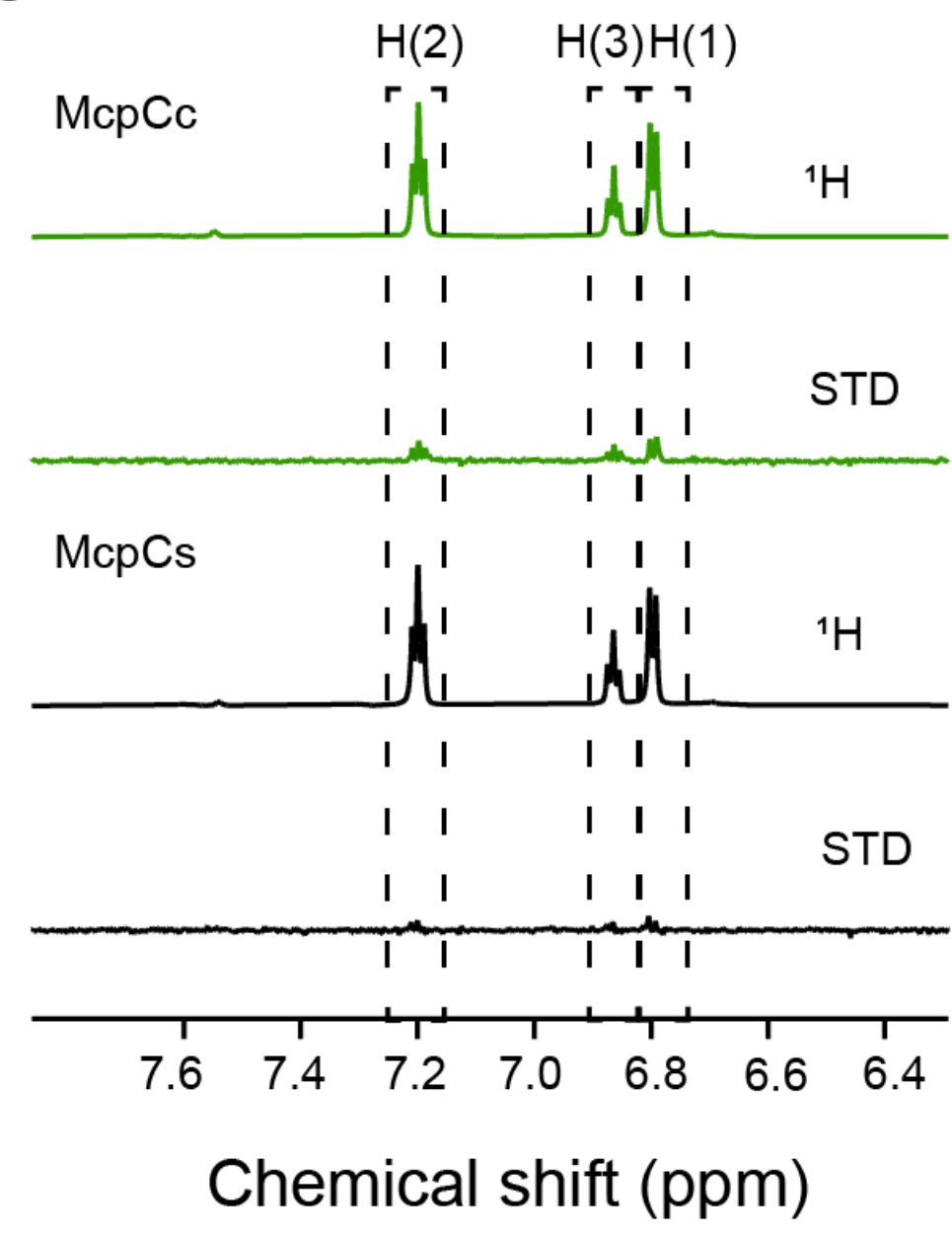


